\title{
Análisis de la nueva regulación del contrato menor en la Ley 9/2017, de 8 de noviembre, de Contratos del Sector Público ${ }^{1}$
}

\section{Analysis of the new regulation of the minor contract law 9/2017, of 8 november, on public sector contracts}

\author{
Roberto Carrodeguas Méndez \\ Ayuntamiento de Peraleda de la Mata (Cáceres) \\ robertocarrodeguas10@hotmail.com
}

\begin{abstract}
NOTA BIOGRÁFICA
Licenciado en Derecho por la Universidad de Santiago de Compostela. Funcionario de la Administración Local con Habilitación de Carácter Nacional. Actualmente, Secretario-Interventor de los Ayuntamientos de Peraleda de la Mata y Valdehúncar (Cáceres). Máster en Contratación Pública Local por el Instituto de Derecho Local de la Universidad Autónoma de Madrid.
\end{abstract}

\section{RESUMEN}

En el Boletín Oficial de Estado número 272, del 9 de noviembre de 2017, se publicó la Ley de Contratos del Sector Público, entrando en vigor el pasado día 9 de marzo. Desde un primer momento, la configuración del contrato menor en la nueva Ley ha despertado un gran interés y preocupación, no solo entre los operadores jurídicos, sino también entre las propias empresas y profesionales que operan en el mercado. A pesar su corta vida, muchos son los interrogantes y dudas que ha generado el nuevo texto legal, proliferando opiniones doctrinales e informes de órganos consultivos en la materia con distinto criterio interpretativo, lo que ha provocado un elevado grado de inseguridad jurídica en el momento de aplicar la norma. Este trabajo pretende efectuar un estudio detallado de la figura del contrato menor y de su actual regulación normativa, analizando, desde un punto de vista práctico, las consecuencias que puede tener la nueva regulación en el ámbito de la Administración Pública. Por último, se exponen una serie de argumentos en defensa del contrato menor que conducen a la conclusión de que una correcta utilización del mismo puede resultar de gran utilidad en el ámbito de la contratación pública local.

\section{PALABRAS CLAVE}

Contratación directa; principios generales; transparencia; simplificación; requisitos; expediente de contratación; aplicación.

\section{ABSTRACT}

In the Official State Gazette number 272, of November 9, 2017, the Public Sector Contracts Law was published, entering into force on March 9. From the outset, the configuration of the minor contract in the new Law has aroused great interest and concern, not only among legal operators, but also among the companies themselves and professionals operating in the market. Despite its short life, there are many questions and doubts that the new legal text has generated, proliferating doctrinal opinions and reports from advisory bodies on the subject with different interpretive criteria, which has caused a high degree of

1 Trabajo fin de Máster de Contratación Pública Local 6. ${ }^{a}$ Edición - Curso 2017/2018, organizado por el Instituto de Derecho Local de la Universidad Autónoma de Madrid. 
REALA. Nueva Época - N. 10, Octubre 2018 - ISSN: 1989-8975 - DOI: 10.24965/reala.v0i10.10557 - [Págs. 56-79]

Análisis de la nueva regulación del contrato menor en la Ley 9/2017, de 8 de noviembre, de Contratos del Sector Público

Roberto Carrodeguas Méndez

legal uncertainty at the time of applying the rule. This paper intends to carry out a detailed study of the minor contract figure and its current regulatory regulation, analyzing, from a practical point of view, the consequences that the new regulation may have in the field of Public Administration. Finally, a series of arguments are presented in defense of the minor contract that lead to the conclusion that a correct use of it can be very useful in the field of local public procurement.

\section{KEYWORDS}

Direct hire; general principles; transparency; simplification; requirements; record of procurement; application.

\section{SUMARIO}

1. PRESENTACIÓN. 2. EL PORQUÉ DE UNA NUEVA REGULACIÓN. 3. ENCAJE DEL CONTRATO MENOR EN EL DERECHO EUROPEO: CONTRATACIÓN DIRECTA VERSUS PRINCIPIOS GENERALES DE LA CONTRATACIÓN PÚBLICA. 4. LA NUEVA REGULACIÓN JURÍDICA DEL CONTRATO MENOR EN LA LEY 9/2017, DE 8 DE NOVIEMBRE, DE CONTRATOS DEL SECTOR PÚBLICO. 4.1. PUNTO DE PARTIDA: LA NECESIDAD DE TRAMITAR EXPEDIENTE DE CONTRATACIÓN EN EL CONTRATO MENOR. 4.2. ANÁLISIS DEL EXPEDIENTE DE CONTRATACIÓN. 4.2.1. Sujeto, objeto y valor estimado del contrato menor. 4.2.2. Duración del contrato menor. 4.2.3. Fiscalización del contrato menor. 4.2.4. Requisitos del contratista. 4.2.5. Informe del órgano de contratación motivando la necesidad del contrato. 4.2.6. Informe del órgano de contratación justificando que no se está alterando el objeto del contrato para evitar la aplicación de las reglas generales de la contratación. 4.2.7. Informe del órgano de contratación justificando que el contratista no ha suscrito más contratos individuales que individual o conjuntamente superen los 40.000 euros en el supuesto de obras o de 15.000 euros cuando se trate de suministro o de servicios. 4.2.8. Perfección del contrato menor. 4.2.9 Ejecución del contrato menor. 4.2.10. Necesidad de dar publicidad a los contratos menores. 4.2.11. Comunicación al Registro Oficial de Contratos del Sector Público y al Tribunal de Cuentas de los contratos menores realizados. 4.3. ¿APLICACIÓN DEL ARTÍCULO 118 DE LA LCSP A TODOS LOS PODERES ADJUDICADORES? 4.4 ALGUNAS CUESTIONES PRÁCTICAS. 5. A MODO DE REFLEXIÓN FINAL. 6. BIBLIOGRAFÍA.

\section{PRESENTACIÓN}

El artículo 1 de la Ley 9/2017, de 8 de noviembre, de Contratos del Sector Público, por la que se transponen al ordenamiento jurídico español las Directivas del Parlamento y del Consejo 2014/23/UE y 2014/24/ UE, de 26 de febrero de 2014 (LCSP) establece que la Ley tiene por objeto regular la contratación del sector público, a fin de garantizar que la misma se ajuste a los principios de libertad de acceso a las licitaciones, publicidad y transparencia de los procedimientos, y no discriminación e igualdad de trato entre los licitadores; y de asegurar, en conexión con el objetivo de estabilidad presupuestaria y control del gasto, y el principio de integridad, una eficiente utilización de los fondos destinados a la realización de obras, la adquisición de bienes y la contratación de servicios mediante la exigencia de la definición previa de las necesidades a satisfacer, la salvaguarda de la libre competencia y la selección de la oferta económicamente más ventajosa.

En el marco de estos principios, la LCSP introduce importantes novedades llamadas a facilitar la lucha contra el fraude y la corrupción, estableciendo un conjunto de medidas destinadas a fomentar la transparencia en los contratos públicos. De entre ellas, destacamos la eliminación del procedimiento negociado sin publicidad por razón de la cuantía y la nueva regulación del contrato menor, que aparenta ser más restrictiva que la anterior, en la medida que introduce nuevos requisitos procedimentales, reduce las cuantías y los tipos de contratos en los que se puede utilizar.

La indebida utilización de la contratación menor mediante el fraccionamiento irregular del objeto del contrato y la falta de negociación efectiva en el extinguido procedimiento negociado sin publicidad por razón de la cuantía favorecieron la proliferación de conductas corruptas y de irregularidades administrativas, vulnerando el principio de integridad en la gestión pública y, por extensión, el principio de buena administración. El contrato menor se articula como un régimen jurídico excepcional, dirigido a atender la necesidad de simplificar el procedimiento administrativo en aquellos supuestos en que ha de primar la agilidad con la que han de ser atendidas determinadas necesidades de reducido importe económico.

Su opacidad y falta de transparencia deberían diseñar este procedimiento como un sistema excepcional. Sin embargo, ocurre todo lo contrario, ya que la experiencia nos demuestra que se ha convertido en 
el instrumento básico para la adjudicación de contratos públicos. Lo que, en principio, podía ser adecuado para cubrir determinadas necesidades de forma rápida, termina siendo una patología endémica del sistema de contratación pública de nuestro días, consecuencia de su utilización indebida, repetitiva, abusiva y generalizada.

Un importante sector doctrinal ha sostenido que la nueva Ley anunciaba una presencia meramente testimonial de la figura del contrato menor ${ }^{2}$. Es difícil aventurar si los poderes adjudicadores harán un uso más racional de la contratación directa, pero lo cierto es que la nueva regulación establece una serie de requisitos que favorecen la transparencia en la contratación pública, pero al mismo tiempo dificultan la agilidad en la contratación, lo que en la práctica puede implicar una importante factura en pérdida de eficacia.

En este contexto, podemos afirmar que la Ley no consigue regular de forma nítida esta figura, generando un elevado grado de inseguridad jurídica. Al mismo tiempo, la redacción del texto legal deja sobre la mesa distintas cuestiones objeto de debate: ¿Se ajusta la nueva regulación a los principios europeos de la contratación pública?; ¿Pretende el legislador un giro copernicano en esta forma de adjudicación de contratos?; ¿Existe una limitación a la celebración de contratos menores con un mismo contratista en al artículo 118.3 LCSP?; ¿Se aplica el artículo 118 LCSP a los PANAPs? Y la más importante de todas las cuestiones que se puedan llegar a suscitar: ¿Es el contrato menor un "contrato necesario»?

A lo largo del presente trabajo se pretende ofrecer respuesta a las cuestiones planteadas, efectuando un análisis minucioso de la figura del contrato menor en la nueva LCSP, en la medida en que este tema está despertando un gran interés, no solo para los aplicadores del Derecho sino también para las propias empresas que operan en el mercado ${ }^{3}$.

Este interés se debe en gran medida al desconcierto y a la falta de seguridad jurídica que existe a la hora de proceder a la aplicación de la nueva normativa sobre esta materia.

Con el ánimo de alcanzar algunas conclusiones que permitan valorar la correcta utilización de esta figura contractual, abordamos su estudio analizando las razones que justifican la nueva regulación dada por el legislador y su encaje en el Derecho Europeo, deteniéndonos en su actual regulación normativa, todo ello, a la luz de la doctrina y jurisprudencia existente en la materia.

Por último, se efectúa una reflexión sobre las razones que han conducido a que los gestores públicos utilicen de manera recurrente el contrato menor para satisfacer sus necesidades, desmontado esa idea demagógica de que la adjudicación directa está siempre vinculada a la corrupción y a la falta de integridad en la contratación.

\section{EL PORQUÉ DE UNA NUEVA REGULACIÓN}

Señala la Junta Consultiva de Contratación Administrativa de Cataluña, en su Informe 14/2014, de 22 de julio, con remisión a otros informes de Juntas Consultivas de Comunidades Autónomas y la del Estado, que el contrato menor comporta una simplificación y una agilización procedimental que hay que calificar de eficientes $y$, sin duda, necesarias en determinadas circunstancias y para determinadas adquisiciones 0 aprovisionamientos. Por lo tanto, la finalidad de esta categoría contractual no es otra que la de posibilitar una satisfacción rápida de determinadas necesidades, a través de un procedimiento ágil y sencillo, dada la escasa cuantía y duración temporal de los contratos mediante los cuales se pretenden cubrir. Sin embargo, su aplicación supone la excepción de los principios de libertad de acceso a las licitaciones y publicidad, así como la inaplicación del deber de salvaguarda de la libre competencia y de selección de la oferta económicamente más ventajosa.

Este último argumento sirve para justificar que la utilización de la figura de los contratos menores haya sido objeto de delimitación en múltiples ocasiones, cuando no de restricción. La configuración de un nuevo régimen jurídico del contrato menor no responde a un capricho del legislador. Y obviamente, si desconocemos el motivo por el cual se adoptan determinadas decisiones, difícilmente las podremos llegar a comprender.

\footnotetext{
2 Al respecto, en el escrito de conclusiones de la Jornada sobre la nueva Ley de Contratos del Sector Público organizada por Transparencia Internacional España el 6 de noviembre de 2017 en la sede de la Fundación Ortega y Gasset-Marañón, GIMENO FELIU indicaba que «los contratos menores son como una bacteria ultrarresistente a los que se les dio una buena radiación y un buen viaje, con la nueva ley se podrán utilizar pero no con el carácter intensivo de antes». https://transparencia.org.es/wp-content/uploads/2017/11/ conten_concl_jornada_nueva_ley_contratos_publicos.pdf.

3 En este sentido, resulta ilustrativo el título del artículo de opinión publicado por MOREO MARROIG en el Blog esPublico: "El Trending Topic del momento: Los contratos menores y el artículo 118 de la Ley 9/2017, de Contratos del Sector Público".
} 
En este sentido, conviene recordar que la regulación vigente del contrato menor hasta la entrada en vigor de la nueva LCSP ha sido objeto de profundas críticas, a nivel europeo y nacional, todo ello, en la medida que las adjudicaciones «a dedo» atentan contra los principios generales de la contratación pública; conllevan falta de transparencia, favorecen la corrupción y generan ineficiencia económica.

Resulta más que evidente que la sociedad del siglo XXI demanda al sector público una contratación transparente, competitiva y eficiente en términos económicos. En este escenario debemos analizar la supervivencia del contrato menor, o si se prefiere, en otros términos, de la adjudicación directa sin pública concurrencia.

Esta figura ha sido utilizada generalmente por las Administraciones Públicas, en especial las entidades locales, para dar mayor celeridad en la satisfacción de necesidades de contratación de bajo importe y duración reducida. Como manifestación del principio de eficacia, se simplifica el procedimiento a seguir para la adjudicación, permitiendo la libre selección del contratista.

Atendiendo a su tamaño y a sus medios, cuando este tipo de Administraciones acuden al mercado para contratar prestaciones de escasa cuantía, no parece racional ni operativo exigirles tramitar expedientes complejos que demoran las necesidades administrativas que pretenden satisfacer con su realización. A esto hay que sumar que la utilización del contrato menor es una posibilidad que incorpora la normativa de contratos para agilizar la contratación administrativa, y que nada impide, que en los supuestos de cuantías que autorizan la suscripción de un contrato menor, el órgano de contratación, para someter su actividad contractual a un mayor control y para favorecer en definitiva la libre concurrencia y la transparencia en la contratación pública, puede acordar la celebración de contratos de cuantía inferior con sujeción a procedimientos abiertos o restringidos, es decir, a licitación pública ${ }^{4}$.

El problema está en que, en muchas ocasiones, la apariencia de legalidad del contrato menor puede convertirse en una vía habitual para incumplir los preceptos legales correspondientes sobre publicidad y sobre procedimiento de adjudicación ${ }^{5}$.

En numerosas ocasiones, los órganos consultivos y fiscalizadores han puesto en el punto de mira esta figura. A pesar de ello, su utilización por los poderes adjudicadores ha sido intensa.

Sin lugar a dudas, en múltiples ocasiones, la eficacia procedimental que se predica del contrato menor puede conllevar un alto precio, que se traduce en la pérdida de transparencia, eficiencia e integridad. El abuso del recurso al contrato menor, así como su utilización indebida mediante el fraccionamiento del objeto del contrato ha provocado la proliferación de mediáticos casos de corrupción (trama Gürtel, caso Palau, operación Pokemon, caso Púnica, entre otros) y de prácticas clientelares, de las que derivan evidentes ineficiencias económicas, y por supuesto, pérdida de legitimación democrática de las instituciones administrativas y políticas 6 .

Como indica GIMENO FELIU, es el mercado de los contratos públicos donde existen «mayores tentaciones» y donde se ofrecen más oportunidades a la corrupción ${ }^{7}$.

Para evitar la utilización abusiva con la que hasta ahora se había usado el contrato menor en nuestro sector público, el legislador ha considerado necesario confeccionar una nueva regulación, articulando al mismo tiempo una alternativa al contrato menor con nuevos procedimientos de adjudicación que permitan contratar de una forma sencilla, eficaz y eficiente. Así pues, la nueva LCSP sienta las bases para confeccionar una nueva cultura de la contratación pública, constituyendo una oportunidad para que los poderes

\footnotetext{
${ }^{4}$ Al respecto, el Informe 40/1995, de 7 de marzo, de la Junta Consultiva de Contratación Administrativa del Estado.

5 Sobre esta cuestión, el Informe de 9/2009, de 15 de junio, de la Junta Consultiva de Contratación Administrativa de Andalucía.

${ }^{6}$ La corrupción genera pérdidas en la economía de la UE que se estiman en unos 120.000 millones de euros al año ( $1 \%$ del PIB europeo) y, conlleva la distorsión del funcionamiento del mercado interior Comunicación de la Comisión Lucha contra la corrupción en la UE, COM (2011) 308 final, de 6 de junio, pág. 3). Lo que explica el interés de las instituciones comunitarias por el control financiero de los contratos públicos. Así se explica la existencia del Reglamento financiero y de la creación de la Oficina de Lucha AntiFraude (OLAF). Vid. T. MEDINAARNAIZ, "Las disposiciones financieras de la Unión Europea y su aplicación a la contratación pública: especial referencia al nuevo Reglamento financiero y sus normas de desarrollo", libro col. Observatorio de los contratos públicos 2012, Aranzadi, Cizur Menor, 2013, págs. 188-190. Resultan también de especial interés los datos aportados por M. VILLORIA y F. JIMENEZ, "La corrupción en España (2004-2010): datos, percepción y efectos, REIS, núm. 138, abril-junio de 2012, pág. 109 y ss.

7 Vid. J. M. GIMENO FELIU, "La Ley de Contratos del Sector Público: ¿una herramienta eficaz para garantizar la integridad? Mecanismos de control de la corrupción en la contratación pública", REDA, núm. 147, págs. 517-535, T. MEDINAARNÁlZ, "Las respuestas normativas al fenómeno de la corrupción en la contratación pública", diario La Ley, núm. 7.382, abril 2010, págs. 1-10; R. RIVERO ORTEGA, R.: "Corrupción y contratos públicos: las respuestas europeas y latinoamericana", en la obra colectiva La corrupción en un mundo globalizado: Análisis interdisciplinar, Ratio Legis, Salamanca, págs. 109-125; y E. JIMÉNEZ FRANCO, "Administración pública y corrupción: iniciativas legislativas de lege ferenda para una nueva cultura de integridad", Actualidad Administrativa, núm. 5, marzo 2012, págs. 538-569.
} 
REALA. Nueva Época - N. 10, Octubre 2018 - ISSN: 1989-8975 - DOI: 10.24965/reala.v0i10.10557 - [Págs. 56-79]

Análisis de la nueva regulación del contrato menor en la Ley 9/2017, de 8 de noviembre, de Contratos del Sector Público

adjudicadores del sector público incentiven un cambio en su manera de contratar, aprovechando las ventajas que ofrecen las nuevas tecnologías a través de la contratación electrónica y abandonando esa idea del "siempre se ha hecho así».

Ahora bien, no debemos presuponer que la adjudicación de un contrato menor por el gestor público encierra siempre un interés oculto, ligando contratación menor con corrupción. Una afirmación de estas características no sería acertada, ya que sólo el abuso de la contratación menor y la tentación de fraccionar el objeto de los contratos pueden llegar a justificar la nueva regulación restrictiva ofrecida por el legislador.

\section{ENCAJE DEL CONTRATO MENOR EN EL DERECHO EUROPEO: CONTRATACIÓN DIRECTA VERSUS PRINCIPIOS GENERALES DE LA CONTRATACIÓN PÚBLICA}

Las nuevas directivas del año $2014^{8}$ sustituyen a la Directiva 2004/18/CE sobre coordinación de los procedimientos de adjudicación de los contratos públicos de obras, de suministro y de servicios y Directiva 2004/17/CE sobre la coordinación de los procedimientos de adjudicación de contratos en los sectores del agua, de la energía, de los transportes y de los servicios postales, aprobadas una década antes, y que habían sido transpuestas al ordenamiento jurídico español a través de la Ley 30/2007, de 30 de octubre, de Contratos del Sector Público -posteriormente derogada y sustituida por el texto refundido de la Ley de Contratos del Sector Público, aprobado por Real Decreto Legislativo 3/2011, de 14 de noviembre-, y la Ley 31/2007 de 30 de octubre, sobre procedimientos de contratación en los sectores del agua, la energía, los transportes y los servicios postales, respectivamente ${ }^{9}$.

Las Directivas sobre contratación pública adoptadas en 2014 proporcionan un conjunto de instrumentos que permite a los Estados miembros realizar un uso más eficiente y estratégico de la contratación pública. Recogen de forma destacada estos principios generales aplicables en la adjudicación de los contratos. De esta manera, la Directiva 2014/24/UE, desde su primer considerando resalta la necesidad de respetar los principios generales en la adjudicación de contratos públicos por o en nombre de las autoridades de los Estados Miembros (una previsión similar se contemplaba el apartado segundo de la Exposición de Motivos de la Directiva 2004/18/CE). Estos principios son citados en numerables ocasiones a lo largo de toda la Exposición de Motivos de la Directiva 2014/24/UE (Considerandos 12, 31, 40, 58, 68, 101, 114 y 136).

No obstante, resulta preciso indicar que las Directivas no reconocen expresamente la figura del contrato menor, entre otros motivos, porque se trata de normas que resultan de aplicación a los contratos públicos que superan determinados umbrales económicos. En otras palabras, las Directivas Comunitarias no pueden condicionar la libertad de los Estados miembros para determinar el modo de adjudicar los contratos que no alcancen los umbrales comunitarios, y muchos menos, los contratos de escasa cuantía que no tienen repercusión en el funcionamiento del mercado interior.

Este último argumento no significa que el Derecho europeo se despreocupe de la contratación de cuantía inferior a la prevista en las Directivas. Existen una serie de principios generales que deben ser respetados.

Bajo estas premisas, el Tribunal Europeo, tras comprobar cómo las Directivas sobre contratos no constituyen cuerpos uniformes y completos de normas sobre contratación pública, sostiene que los Estados siguen siendo libres para mantener o adoptar normas sustantivas y procedimentales que disciplinen los contratos públicos, pero, eso sí, «a condición de que se respeten todas las disposiciones aplicables del Derecho comunitario y, en particular, las prohibiciones derivadas de los principios consagrados por el Tratado» ${ }^{10}$.

No obstante, la argumentación jurídica expuesta no debe traducirse en modo alguno en considerar que el mantenimiento del contrato menor en nuestra legislación interna supone una vulneración del Derecho de

${ }^{8}$ Las Directivas 2014/24/UE («Directiva Clásica»), 2014/23/UE («Directiva relativa a las concesiones») y 2014/25/UE («Directiva sobre servicios públicos») del Parlamento y del Consejo.

9 Sobre el contenido de estas Directivas resulta preciso destacar: J. M. GIMENO FELIÚ, El nuevo paquete legislativo comunitario sobre contratación pública. De la burocracia a la estrategia. (El contrato público como herramienta del liderazgo institucional de los poderes públicos), Aranzadi, Cizur Menor, 2014; J. A. MORENO MOLINA, "La cuarta generación de Directivas de la Unión Europea sobre contratos Públicos", en libro colectivo Observatorio de los Contratos Públicos 2012, Aranzadi, Cizur Menor, 2013 , págs. 115 a 163.

10 En este sentido resulta muy ilustrativa la sentencia del TJCE de 13 de octubre de 2005, asunto C 458/03, Parking Brixen $\mathrm{GMBH}$, cuando concluye que «pese a que, en el estado actual del Derecho comunitario, los contratos de concesión de servicios públicos se encuentran excluidos del ámbito de aplicación de la Directiva 92/50, las autoridades públicas que los celebren están obligadas no obstante a respetar, en general, las normas fundamentales del Tratado CE y, en especial, el principio de no discriminación por razón de la nacionalidad». 
REALA. Nueva Época - N. 10, Octubre 2018 - ISSN: 1989-8975 - DOI: 10.24965/reala.v0i10.10557 - [Págs. 56-79]

Análisis de la nueva regulación del contrato menor en la Ley 9/2017, de 8 de noviembre, de Contratos del Sector Público

Roberto Carrodeguas Méndez

la Unión. Más bien todo lo contrario. Los Estados tienen libertad para mantener este tipo de contratos, sobre la base de que presentan escaso interés transfronterizo. El contrato menor no solo existe en España, sino también en otros países de nuestro entorno, y encuentra su razón de ser en su escasa cuantía y duración, que implica implícitamente una disminución de la intensidad de la aplicación de los principios generales europeos.

En apoyo de este argumento, destacamos la Comunicación interpretativa de la Comisión Europea de 23 de junio de 2006, sobre el Derecho comunitario aplicable en la adjudicación de contratos no cubiertos o sólo parcialmente cubiertos por las Directivas sobre contratación pública ${ }^{11}$. La Comunicación interpretativa de la Comisión sobre el Derecho comunitario aplicable a la adjudicación precisa que, si bien las Directivas sobre contratación pública no se aplican a todos los contratos públicos, las entidades adjudicadoras de los Estados miembros deben cumplir las normas y principios del Tratado CE en todas las adjudicaciones de contratos públicos que entren en el ámbito de aplicación del mismo.

La Comunicación, recogiendo la jurisprudencia comunitaria, precisa que las normas derivadas del Tratado CE se aplican sólo en la adjudicación de contratos que guarden suficiente relación con el funcionamiento del mercado interior. A este respecto, el TJUE ha declarado que, en determinados casos, debido a «circunstancias específicas, como la escasa trascendencia económica», una adjudicación de contrato carecerá de interés para los operadores económicos establecidos en otros Estados miembros. En tal caso, «los efectos sobre las libertades fundamentales (...)» son «demasiado aleatorios y demasiado indirectos» como para justificar la aplicación de normas derivadas del Derecho primario comunitario ${ }^{12}$. Por todo ello, corresponderá a cada entidad adjudicadora decidir si la adjudicación del contrato prevista encierra potencialmente interés para los operadores económicos de otros Estados miembros. La Comisión estima que esta decisión deberá basarse en una evaluación de las circunstancias específicas del caso, tales como el objeto del contrato, su cuantía estimada, las características particulares del sector (tamaño y estructura del mercado, prácticas comerciales, etc.), así como el lugar geográfico de ejecución del contrato.

En la línea apuntada, la Sentencia del TJUE de 16 de abril de 2015, Asunto C-42/14, indica, por lo que respecta a los principios de igualdad de trato y de no discriminación, así como a la obligación de transparencia, que debe reconocerse a los Estados miembros un cierto margen de apreciación para adoptar medidas con el objeto de garantizar el respeto de dichos principios, que vinculan a las entidades adjudicadoras en todos los procedimientos de adjudicación de un contrato público.

Por otra parte, la Sentencia del Tribunal de Justicia (Sala Cuarta) de 23 de noviembre de 2009, Serrantoni Srl y Consorzio stabile edili Scrl contra Comune di Milano, Asunto C-376/08, en cuanto a los principios de igualdad de trato y de transparencia, reconocía a los Estados miembros un cierto margen de apreciación para adoptar medidas con el objeto de garantizar el respeto de dichos principios, que vinculan a las entidades adjudicadoras en todos los procedimientos de adjudicación de un contrato público. Son, en todo caso, los Estados miembros los que mejor pueden determinar, a la luz de consideraciones históricas, jurídicas, económicas o sociales que les son propias, las situaciones propicias para la aparición de comportamientos que pueden suponer el menoscabo de dichos principios.

De esta manera, podríamos concluir que la aplicación de los principios generales de la contratación pública se ve minorada cuando un contrato no presente, a juicio del Derecho comunitario, «interés transfronterizo». Los principios comunitarios inherentes a la contratación pública son de directa aplicación a cualquier contrato, sea o no "armonizado», evitando que existan en la práctica ámbitos de la contratación pública exentos en función del umbral, pero siempre que concurra interés transfronterizo. Así lo entendió el TJUE (Sala Quinta) en la sentencia de 16 de abril de 2015, en el asunto C-278/14, al señalar aplicable a un contrato, no sujeto a la Directiva (valor estimado de 58.600 euros) pero que presentaba interés transfronterizo cierto, las normas fundamentales y los principios generales del Tratado, en particular, los principios de igualdad de trato y no discriminación, así como la obligación de transparencia.

Atendiendo a la argumentación jurídica expuesta, podemos afirmar que, salvo en excepcionales ocasiones, la celebración de un contrato menor, por la escasa cuantía que representa, resulta perfectamente

11 Comunicación 2006/C 179/02), publicada en el Diario Oficial de Unión Europa 01.08.2016 cuya legalidad y conformidad con el Derecho europeo fue confirmada por la STJUE de 20 de mayo de 2010, en el asunto T-258/06, que resolvió el recurso de anulación planteado contra la Comunicación por Alemania, al que se adhirieron como partes coadyuvantes Francia, Austria, Polonia, Países Bajos, Grecia, Reino Unido de Gran Bretaña e Irlanda del Norte y el Parlamento Europeo.

12 Asunto Coname, considerando 20 
compatible con el Derecho de la Unión, a la luz de la interpretación efectuada por la jurisprudencia comunitaria. Ahora bien, esta última afirmación no debe conllevar automáticamente a una interpretación flexible que generalice la utilización indebida y abusiva de los contratos menores, debiendo los Estados miembros de la Unión Europea, entre ellos España, potenciar una contratación pública, en la que los principios básicos de igualdad, no discriminación y transparencia se conviertan en la guía a seguir para configurar los procedimientos de adjudicación de sus contratos públicos.

Así se ha puesto de manifiesto en la preocupación mostrada por Unión Europea, plasmada en la Recomendación de Decisión del Consejo de 27 de julio de $2016^{13}$, en la que se advierte que en nuestro país existe una «falta de mecanismos de control a priori y a posteriori suficientes que obstaculiza la aplicación correcta y uniforme de la legislación en materia de contratación pública»; así como una ausencia de efectiva transparencia dada la «baja tasa de publicación de los anuncios de contratos», «el correlativo abuso de procedimiento negociado sin publicación previa y las adjudicaciones directas».

No en vano, el propio TJUE ha calificado la celebración ilegal de contratos de adjudicación directa como la infracción «más grave del Derecho comunitario en materia de contratos públicos» (STJUE de 11 de enero de 2005, Stadt Halle, apartado 37).

\section{LA NUEVA REGULACIÓN JURÍDICA DEL CONTRATO MENOR EN LA LEY 9/2017, DE 8 DE NOVIEMBRE, DE CONTRATOS DEL SECTOR PÚBLICO}

\subsection{Punto de partida: la necesidad de tramitar expediente de contratación en el contrato menor}

El artículo 131 de la LCSP establece que el contrato menor es uno de los procedimientos de adjudicación de los contratos de las Administraciones Públicas, señalando el apartado 3 del precepto que «los contratos menores podrán adjudicarse directamente a cualquier empresario con capacidad de obrar y que cuente con la habilitación profesional necesaria para realizar la prestación, cumpliendo con las normas establecidas en el artículo 118».

Por su parte, el artículo 118 del texto legal recoge una serie de reglas para la tramitación de los expedientes de contratación de los contratos menores.

Junto al artículo 118 de la LCSP, la LCSP dedica otros 10 artículos, una disposición adicional y una disposición final a la regulación del contrato menor. De la lectura del texto legal, observamos que el legislador apuesta por mantener su existencia. Pero lo hace en términos diferentes al TRLCSP en la medida que presenta importantes novedades como la reducción de los umbrales máximos para su utilización, los tipos de contratos en los que se puede utilizar y, sobre todo, se añaden nuevos requisitos procedimentales para su tramitación.

Siguiendo la Recomendación de la Comisión Europea de 27 de julio de 2016, la LCSP elimina el procedimiento negociado sin publicidad por razón de la cuantía y limita los contratos menores. Como conclusión inicial, podemos afirmar que el contrato menor adquiere naturaleza residual. Esta intención se ve plasmada en la propia Exposición de Motivos, cuando al referirse al procedimiento simplificado, afirma que «...en este procedimiento se habilita además una tramitación especialmente sumaria para contratos de escasa cuantía que ha de suponer la consolidación de la publicidad y la eficiencia en cualquier contrato público, reduciendo la contratación directa a situaciones extraordinarias».

Cuantía y duración siguen siendo los elementos esenciales de la definición del contrato menor. DE SOLAS RAFECAS lo calificó como procedimiento especial de adjudicación ${ }^{14}$. Esta naturaleza jurídica se confirmaba en el TRLCSP, al incluir el contrato menor en el artículo 138.3, dedicado a los «procedimientos de adjudicación». El legislador de 1995, y sus sucesores, defienden y potencian la utilización de este procedimiento ${ }^{15}$. Por el contrario, el legislador actual manifiesta una firme voluntad de convertir la transparencia en

\footnotetext{
13 Recomendación de Decisión del Consejo por la que se formula una advertencia a España para que adopte medidas dirigidas a la reducción del déficit que se considera necesaria para poner remedio a la situación de déficit excesivo.

14 DE SOLAS RAFECAS, J. M: "Los procedimientos de selección de contratistas y de adjudicación de los contratos de la Administración, y en especial del contrato de obras públicas, en el Proyecto de Ley de Contratos de la Administraciones Públicas", dentro de las Jornadas sobre Contratación Pública organizadas por la Universidad de Valladolid en 1993. Ed. Marcial Pons-Cámara de Contratistas de Castilla y León. Madrid 1996. Pág. 86.

15 El Preámbulo de la Ley 13/1995, recoge en el preámbulo, apartado 2.6 que «También son dignas de mencionarse algunas otras de las medidas introducidas, como son: potenciación de los contratos menores...»
} 
principio básico que debe guiar la contratación pública y camina hacia un escenario en que la contratación menor tenga carácter residual ${ }^{16}$.

Al igual que ya sucedía en el TRLCSP, la celebración de un contrato menor exige, en todo caso, la tramitación de un expediente administrativo. La simplificación del procedimiento a través de la celebración del contrato menor no puede implicar la ausencia total del expediente de contratación ${ }^{17}$. No han sido pocos los gestores públicos que han confundido la contratación menor con la contratación verbal, proscrita por nuestro Derecho interno con la única excepción de los supuestos de emergencia.

Las cuantías previstas en el texto legal para celebrar un contrato menor tienen de carácter de máxi$\operatorname{mos}^{18}$. Con acierto, el texto legal utiliza ahora el concepto de "valor estimado» para hacer referencia al límite cuantitativo ${ }^{19}$.

Por el contrario, los requisitos legales tienen el carácter de mínimos. Nada impide que se puedan agregar todas aquellas actuaciones que el órgano de contratación estime oportunas o convenientes para mayor garantía del procedimiento. Esta posibilidad ya había sido admitida por la Junta Consultiva de Contratación Administrativa del Estado en el Informe 10/98, de 11 de junio, en el que afirmaba que nada se opone a que en el expediente del contrato menor "se incorporen, además de los documentos resultantes del artículo 57 , la propuesta de contratación en la que se reflejan las prestaciones a realizar, periodicidad y plazos de ejecución, periodicidad de pagos y otras circunstancias para la mejor concreción del contrato, pues con ello no sólo se dará cumplimiento a determinados requisitos del artículo 11 de la Ley de Contratos de las Administraciones Públicas, sino que además se contribuirá a la mejor y más concreta definición de los derechos y obligaciones de las partes que, por inexistencia de pliego de cláusulas administrativas particulares no pueden figurar en el mismo».

Para comprender el alcance y relevancia de la nueva regulación del contrato menor, concentrada básicamente en el precitado artículo 118 de la LCSP, consideramos de interés efectuar una breve referencia a su tramitación parlamentaria; sobre todo, si tenemos en cuenta que el resultado final de la redacción del precepto es fruto de las necesarias transacciones que tuvieron lugar en el seno de la Comisión de Hacienda y Administración Pública del Congreso, encargada de la tramitación del proyecto de Ley.

La indefinición, falta de claridad y deficiente técnica legislativa utilizada obligará, tal y como señala la Junta Consultiva de Contratación Administrativa de Aragón en el Informe 3/2018, de 13 de febrero, a tener especialmente en cuenta la voluntad del legislador a la hora de analizar el texto resultante del artículo ${ }^{20}$. El texto inicial del artículo 118 recogido en el proyecto de Ley aprobado por el Gobierno (BOCG Congreso de los Diputados, Serie A, núm. 2-1, de 2 de diciembre de 2016) mantenía una redacción similar al artículo 138 TRLCSP ${ }^{21}$. El proyecto fue sometido a plazo de enmiendas que, tras diversas ampliaciones, finalizó el 2 de

${ }^{16}$ La Exposición de Motivos de la LCSP fija como uno de los objetivos que inspira la regulación de la misma «lograr una mayor transparencia en la contratación pública».

17 Informe Junta Consultiva de Contratación Administrativa de Andalucía número 2/2016, de 25 de febrero, sobre el contrato menor y el fraccionamiento de los contratos.

18 Disposición Final Primera LCSP: A los mismos efectos previstos en el párrafo anterior tendrán la consideración de mínimas las exigencias que para los contratos menores se establecen en el artículo 118.1.

19 Resulta interesante la lectura Circular de la Abogacía del Estado de 30 de julio de 2008 y el Dictamen 1/2008, de 20 de mayo, de la Junta Superior de Contratación Administrativa de la Generalitat Valenciana que concluyen que en los límite cuantitativos previsto en la ley 30/2007 para los contratos menores no se incluye el IVA.

20 La Junta Consultiva de Contratación Administrativa de Aragón en su informe aclara que: «La falta de claridad del apartado 3 del art. 118 LCSP, tal como ponen de manifiesto las cuestiones que se plantean en la consulta obligan a que por vía interpretativa deba determinarse el exacto alcance de sus prescripciones, en aras a una mayor seguridad jurídica que la que resulta del tenor literal del texto legal. Si bien la dogmática jurídica moderna se basa en gran medida en la autonomía de la "voluntas legis" respecto a la "voluntas legislatoris", en función de elementos como la interpretación sistemática o "contexto" o "la realidad social del tiempo en que han de ser aplicadas", como se establece en el art. 3.1 del Código Civil, en este caso la proximidad de la aprobación obliga a tener especialmente en cuenta la voluntad del legislador, el "espíritu y finalidad" que se ha pretendido dar a la norma, tal como se desprenden de los trabajos parlamentarios, dado el protagonismo inhabitual que la tramitación parlamentaria ha tenido en la configuración de la nueva Ley. Por otra parte, esa importancia que ha tenido en la configuración de la LCSP la tramitación parlamentaria comporta dificultades adicionales para aplicar interpretaciones sistemáticas o para confiar excesivamente en la exposición de motivos, que están más cercanas a las líneas y previsiones a que respondía el proyecto de Ley aprobado por el Gobierno».

${ }^{21}$ La redacción inicial del precepto en el proyecto de Ley era la siguiente: «Artículo 118. Expediente de contratación en contratos menores.

1. Se consideran contratos menores los contratos de valor estimado inferior a 50.000 euros, cuando se trate de contratos de obras, o a 18.000 euros, cuando se trate de contratos de suministro o de servicios, en el ámbito estatal.

En los contratos menores la tramitación del expediente solo exigirá la aprobación del gasto y la incorporación al mismo de la factura correspondiente, que deberá reunir los requisitos que las normas de desarrollo de esta Ley establezcan. 
marzo de 2017, durante el cual, en relación con este artículo se presentaron las siguientes (BOCG Congreso de los Diputados, Serie A, núm. 2-2, de 16 de marzo de 2017):

- Enmienda núm. 102, del Grupo Parlamentario Confederal de Unidos Podemos-En Comú Podem-En Marea, apartado 1.

- Enmienda núm. 580, del Grupo Parlamentario Socialista, apartado 1.

- Enmienda núm. 581, del Grupo Parlamentario Socialista, apartado 1.

- Enmienda núm. 582, del Grupo Parlamentario Socialista, apartado nuevo.

- Enmienda núm. 583, del Grupo Parlamentario Socialista, apartado nuevo.

- Enmienda núm. 584, del Grupo Parlamentario Socialista, apartado nuevo.

- Enmienda núm. 585, del Grupo Socialista, apartado nuevo.

La Ponencia, a la vista del contenido de las enmiendas, elaboró en su informe un nuevo texto del precepto, que finalmente resultó aprobado por la cámara legislativa. De esta manera, se modifica la redacción inicial del artículo 118.1, párrafo primero, como consecuencia de la aceptación de la enmienda transaccional procedente de la enmienda 102, reduciendo el umbral por debajo del cual los contratos son considerados como menores. Fruto de la enmienda 581, se añade además al párrafo segundo del apartado primero un nuevo requisito del expediente, a saber: el informe del órgano de contratación motivando la necesidad del contrato. Finalmente, se adiciona al artículo 118 el actual apartado $3 .^{\circ}$, procedente de la enmienda 583 y apartado $4 .^{\circ}$, procedente de la enmiendas 585 y 507 , presentadas todas ellas por el Grupo Socialista ${ }^{22}$.

La redacción final dada al precepto por el legislador implica la necesidad de tramitar un auténtico expediente de contratación con la incorporación de nuevos requisitos a los que tradicionalmente se habían venido exigiendo; reduce el ámbito objetivo y disminuye el importe de la contratación menor.

\subsection{Análisis del expediente de contratación}

A la vista de la redacción dada al precepto, procedemos a abordar el análisis de la regulación del expediente de contratación del contrato menor en la nueva LCSP.

\subsubsection{Sujeto, objeto y valor estimado del contrato menor}

La nueva LCSP reserva la utilización de los contratos menores para los casos en los que la entidad contratante sea una Administración Pública. Como analizaremos más adelante, para los PANAPs el legislador utiliza la expresión «adjudicación directa», pero en ningún caso habla de contratos menores.

La LCSP limita la utilización del contrato menor al contrato de obras, servicios y suministros (artículo 118.1 LCSP). El importe máximo de los contratos menores de obras no puede superar, IVA excluido, los $40.000 €$ (frente a los $50.000 €$ del TRLCSP) y los de servicios y suministros $15.000 €$ (frente a los $18.000 €$ en el TRLCSP).

La LCSP mantiene tres excepciones muy especiales a estas limitaciones:

a) Los contratos de servicios sanitarios de urgencia de valor estimado inferior a 30.000 euros (artículo 131.4 LCSP).

Para proceder a la contratación en estos casos bastará con que, además de justificarse la urgencia, se determine el objeto de la prestación, se fije el precio a satisfacer por la asistencia y se designe por el órgano de contratación la empresa a la que corresponderá la ejecución.

b) Los contratos que tengan por objeto la prestación de actividades docentes en centros del sector público desarrolladas en forma de cursos de formación o perfeccionamiento del personal al servicio de

2. En el contrato menor de obras, deberá añadirse, además, el presupuesto de las obras, sin perjuicio de que deba existir el correspondiente proyecto cuando normas específicas así lo requieran. Deberá igualmente solicitarse el informe de las oficinas o unidades de supervisión a que se refiere el artículo 233 cuando el trabajo afecte a la estabilidad, seguridad o estanqueidad de la obra».

${ }_{22}$ Con relación a la tramitación parlamentaria de la ley, resulta de interés la lectura del artículo publicado en El Consultor de los Ayuntamientos, núm. 3, Marzo 2018, pág. 70, Editorial Wolters Kluwer. La nueva regulación del contrato menor en la Ley 9/2017, de 8 de noviembre, de Contratos del Sector Público: un cambio sustancial. ALBÓNIGA ITURBE, Jesús Matías; LÓPEZ DE LA RIVA CARRASCO, Federico Andrés. 
la Administración o cuando se trate de seminarios, coloquios, mesas redondas, conferencias, colaboraciones o cualquier otro tipo similar de actividad, siempre que dichas actividades sean realizadas por personas físicas (artículo 310 LCSP).

Esta excepción no es aplicable a los contratos celebrados con personas jurídicas. Además, al utilizar expresiones genéricas de «seminarios, coloquios, mesas redondas, conferencias, colaboraciones o cualquier otro tipo similar de actividad» permiten considerar incluidos en los mismos los «cursos», sin que éstos, para la aplicación del precepto, hayan de tener por objeto la formación o el perfeccionamiento del personal al servicio de la Administración ${ }^{23}$.

c) La suscripción a publicaciones y la contratación del acceso a la información contenida en bases de datos especializadas siempre que no estén sujetos regulación armonizada (D. A. 9. ${ }^{a}$ LCSP).

La suscripción a revistas y otras publicaciones, cualquiera que sea su soporte, así como la contratación del acceso a la información contenida en bases de datos especializadas, y en la medida en que resulten imprescindibles, la contratación de los servicios necesarios para la suscripción o la contratación citadas anteriormente, podrán efectuarse, cualquiera que sea su cuantía siempre que no tengan el carácter de contratos sujetos a regulación armonizada, de acuerdo con las normas establecidas en esta Ley para los contratos menores y con sujeción a las condiciones generales que apliquen los proveedores, incluyendo las referidas a las fórmulas de pago. El abono del precio, en estos casos, se hará en la forma prevista en las condiciones que rijan estos contratos, siendo admisible el pago con anterioridad a la entrega o realización de la prestación, siempre que ello responda a los usos habituales del mercado.

Como novedad, con respecto a la regulación que presentaba en el TRLCSP esta excepción, destacar que la nueva LCSP también las considera aplicables «en la medida en que resulten imprescindibles, a la contratación de los servicios necesarios para la suscripción o la contratación citadas anteriormente».

Atendiendo al tenor literal del artículo 318 b) y de la Disposición Adicional 9. ${ }^{\text {a }}$ de la LCSP, consideramos que las tres excepciones analizadas resultan también de aplicación a los contratos adjudicados por los PANAPs.

Por otra parte, dispone el artículo 308.2 de la LCSP que en ningún caso la entidad contratante podrá instrumentar la contratación de personal a través del contrato de servicios, incluidos los que por razón de la cuantía se tramiten como contratos menores. Fuera de estos tipos contractuales no resulta admisible la figura del contrato menor. De esta manera no resulta posible su aplicación a los contratos patrimoniales, tal y como ya había señalado la Junta Consultiva de Contratación Administrativa del Estado en el Informe 47/11, de 1 de marzo de $2012^{24}$.

Tampoco resulta admisible a los contratos administrativos especiales. Esta posibilidad también fue rechazada por la Junta Consultiva de Contratación Administrativa del Estado en el Informe 38/05, 26 de octubre de $2005^{25}$.

La posibilidad de utilizar el contrato menor en los contratos de gestión de servicio público tradicionalmente no ha sido admitida. El precitado Informe 38/05 indicaba que era evidente que en la tramitación parlamentaria de la anterior Ley fue rechazada la propuesta de inclusión de la categoría de contrato menor en los de gestión de servicios públicos, refiriéndose en su artículo $158.3^{\circ}$ a un supuesto concreto que se asemejaba a las características de los contratos menores, pero limitado exclusivamente a los que tenían por objeto prestaciones sanitarias. La nueva LCSP insiste en rechazar esa posibilidad, al no admitir la enmienda 580 propuesta por el Grupo Parlamentario Socialista para incluir a los contratos de concesión de servicios en el apartado 1 del artículo 118 de la LCSP.

En el caso del contrato de obras, la LCSP, al igual que ya lo hacía el TRLCSP, exige el correspondiente proyecto cuando normas específicas así lo requieran, así como el informe de las oficinas o unidades de su-

\footnotetext{
${ }^{23}$ Al respecto, el Informe 19/02, de 13 de junio de 2002, de la Junta Consultiva de Contratación Administrativa del Estado.

24 En el citado informe, la Junta Consultiva de Contratación Administrativa entiende que al estar excluidos del Texto refundido de la Ley de Contratos del Sector Público los contratos patrimoniales, no pueden aplicarse a los mismos las modalidades que son propias de las normas que regulan tales contratos, como el procedimiento negociado y el contrato menor, pudiendo aplicar en cada caso la subasta, el concurso o la adjudicación directa.

${ }^{25}$ En el citado informe, la Junta Consultiva de Contratación Administrativa concluye que la figura de los contratos menores no resulta aplicable a los contratos administrativos especiales, por no estar admitida expresamente para los mismos y resultar incompatible con el régimen jurídico tal como resulta del artículo 8 de la Ley de Contratos de las Administraciones Públicas.
} 
REALA. Nueva Época - N. 10, Octubre 2018 - ISSN: 1989-8975 - DOI: 10.24965/reala.v0i10.10557 - [Págs. 56-79]

Análisis de la nueva regulación del contrato menor en la Ley 9/2017, de 8 de noviembre, de Contratos del Sector Público

Roberto Carrodeguas Méndez

pervisión a que se refiere el artículo 235 cuando el trabajo afecte a la estabilidad, seguridad o estanqueidad de la obra.

En cuanto a la naturaleza de las prestaciones a contratar, los órganos de fiscalización externa y los consultivos han puesto de manifiesto en reiteradas ocasiones la necesidad de utilizar sólo los contratos menores para satisfacer necesidades puntuales y esporádicas, concretas y perfectamente definidas. No obstante, del texto de la LCSP no se puede llegar a tal conclusión. Es más, dos enmiendas al anteproyecto en este sentido fueron rechazadas.

\subsubsection{Duración del contrato menor}

Los contratos menores definidos en el apartado primero del artículo 118 no podrán tener una duración superior a un año ni ser objeto de prórroga (artículo 29.8 LCSP). En idénticos términos se manifestaba el derogado artículo 23.3 TRLCSP.

El contrato menor no debe ser superior a un año, aunque lógicamente puede extenderse a dos ejercicios presupuestarios, debiendo tramitarse, desde el punto de vista presupuestario, como un gasto de carácter plurianual, siendo de aplicación las limitaciones establecidas en el artículo 174 del Real Decreto Legislativo 2/2004, de 5 de marzo, por el que se aprueba el texto refundido de la Ley Reguladora de las Haciendas Locales -TRLRHL-.

Este límite temporal condiciona la celebración de determinados contratos. Así, por poner un ejemplo, es habitual en la Administración Pública que los contratos de servicios de dirección de obra, atendiendo a su cuantía, se adjudiquen por contrato menor. No obstante, con buena lógica, el cómputo del plazo de duración del contrato de servicios de dirección de obras o la gestión integrada de proyectos deben sumarse el plazo del contrato de obras al que están vinculados más el plazo estimado para proceder a la liquidación de las obras, formando parte del mismo el período de garantía del mencionado contrato de obras. Todo ello, implica la imposibilidad de celebrar un contrato menor cuando el plazo de duración supere el año ${ }^{26}$.

Por idéntica razón no será posible contratar los servicios de defensa jurídica y judicial de una Administración cuando el contrato tenga una duración superior al año ${ }^{27}$. A este respecto, recientemente por un encadenamiento de contratos menores de asesoramiento jurídico han sido condenadas ocho personas por delito de prevaricación ${ }^{28}$.

Como anteriormente se ha apuntado, aunque no tenga reflejo expreso en el texto legal, debe recordarse que el contrato menor sólo puede ser utilizado para atender a necesidades de carácter puntual y esporádico, concretas y perfectamente definidas ${ }^{29}$.

Su utilización para fines distintos, sin atender a estas limitaciones y/o fraccionando el objeto del contrato para eludir la licitación ha desembocado en condenas penales por delito de prevaricación tipificado en el artículo 404 del Código Penal ${ }^{30}$.

\subsubsection{Fiscalización del contrato menor}

El artículo 219.1 TRLRHL dispone que no estarán sometidos a intervención previa los gastos de material no inventariable, contratos menores, así como los de carácter periódico y demás de tracto sucesivo, una vez intervenido el gasto correspondiente al período inicial del acto o contrato del que deriven o sus modificaciones, así como otros gastos menores de 3.005,06 euros que, de acuerdo con la normativa vigente, se hagan efectivos a través del sistema de anticipos de caja fija. En otras palabras, los contratos menores solamente

${ }_{26}$ Al respecto, el Informe 27/2011, de 15 de diciembre de 2011, de la Junta Consultiva de Contratación Administrativa del Estado.

27 Al respecto, el Informe 30/2012, de 7 de mayo, de la Junta Consultiva de Contratación Administrativa del Estado.

28 Sentencia 233/2017, de 6 de octubre de 2017, del Juzgado de lo Penal número 1 de Melilla.

${ }^{29}$ Esta exigencia ha sido reiterada en multitud de ocasiones por el Tribunal de Cuentas y sus homólogos autonómicos, así como por las juntas consultivas (Informes Junta Consultiva de Contratación Administrativa del Estado 60/08, 2/2016; Informe Junta Consultiva de Contratación Administrativa de Canarias 8/2016; Informe Junta Consultiva de Contratación Administrativa de Cataluña 14/2014; Dictamen del Consejo Consultivo de Canarias 128/2016; Informe del Tribunal de Cuentas 1039/2015; 1151/2016; 1189/2016; Informe Sindicatura de Cuentas de Asturias 30 de octubre de 2014...)

30 Sobre las consecuencias penales de la indebida utilización del contrato menor, destacamos el artículo "El fraccionamiento de los contratos menores y su no fiscalización: consecuencias penales". Revista de Derecho Local, núm. 44, Jorge GARCÍA HERNÁNDEZ. 
REALA. Nueva Época - N. 10, Octubre 2018 - ISSN: 1989-8975 - DOI: 10.24965/reala.v0i10.10557 - [Págs. 56-79]

Análisis de la nueva regulación del contrato menor en la Ley 9/2017, de 8 de noviembre, de Contratos del Sector Público

Roberto Carrodeguas Méndez

requieren la aprobación del gasto y la incorporación al mismo de la factura, pero no se someten a fiscalización previa (fase A y D) pero sí a la intervención de las fases $\mathrm{O}$ y $\mathrm{P}^{31}$.

\subsubsection{Requisitos del contratista}

El artículo 65 de la LCSP determina que solo podrán contratar con el sector público las personas naturales o jurídicas, españolas o extranjeras, que tengan plena capacidad de obrar, no estén incursas en alguna prohibición de contratar, y acrediten su solvencia económica y financiera y técnica o profesional o, en los casos en que así lo exija esta Ley, se encuentren debidamente clasificadas. Asimismo, los contratistas deberán contar con la habilitación empresarial o profesional que, en su caso, sea exigible para la realización de las prestaciones que constituyan el objeto del contrato.

Bajo estas premisas, el artículo 131.3 de la LCSP determina que los contratos menores podrán adjudicarse directamente a cualquier empresario con capacidad de obrar y que cuente con la habilitación profesional necesaria para realizar la prestación, cumpliendo con las normas establecidas en el artículo 118.

No pueden eludirse en estos contratos de escasa cuantía las normas esenciales de toda la contratación administrativa y las normas propias de la aprobación de gastos, y en especial, de la necesaria capacidad jurídica del contratista ${ }^{32}$.

Por esto motivo, no se podrá admitir la celebración de un contrato menor con una comunidad de bienes, por carecer de personalidad jurídica; por el contrario, si será posible hacerlo con una sociedad civil (salvo en el supuesto del artículo 1669 del Código Civil sin que en ningún caso sea exigible, por no ser posible su inscripción en el Registro Mercantil) ${ }^{33}$. Y también serán de aplicación las prohibiciones generales para contratar y las causas de incompatibilidad ${ }^{34}$.

Sobre la habilitación empresarial exigida por el artículo 131.3 de la LCSP, debe entenderse como un requisito de aptitud o capacidad, nunca de solvencia ${ }^{35}$; requisito que debe interpretarse de manera restrictiva, según Resolución 140/2011, del Tribunal Administrativo Central de Recursos Contractuales.

Sobre la acreditación documental de estos requisitos, podríamos indicar que existe cierta relajación, fruto de que la exigencia sistemática de la documentación para acreditar estos requisitos formales podría suponer una desnaturalización del propio concepto de contrato menor, caracterizado por la simplificación procedimental inherente al mismo ${ }^{36}$.

No obstante, es evidente que, si el órgano de contratación tiene dudas sobre la falta de alguno o algunos de los requisitos de capacidad del contratista elegido, debe cerciorarse previamente de su concurrencia, debiendo solicitar la acreditación documental de los mismos. En este sentido, la Junta Consultiva de Contratación Administrativa de Aragón, en el Informe 7/2016, de 20 de abril, al analizar un supuesto de incompatibilidad para contratar, indica que «es indiferente que las prestaciones se lleven a cabo a través del régimen jurídico, excepcional, de los contratos menores, pues la limitación de la exigencia de requisitos de la capacidad de obrar ha de entenderse en el sentido de que no es preciso acreditar documentalmente la misma. Sin embargo, evidentemente, si quien suministra se encuentra en prohibición de contratar y esta circunstancia es del conocimiento del órgano de contratación, como es evidente que así lo es, debe tenerla en cuenta. En este sentido se ha pronunciado el Informe 1/2009, de 25 de septiembre, de la Junta Consultiva del Estado».

Sobre este extremo insiste el informe de la IGAE de 29 de julio de 2016 al precisar que en los contratos menores no tiene por qué quedar constancia de la acreditación de la solvencia técnica del empresario, de-

31 Hay que tener en cuenta que la Audiencia de Cuentas de Canarias, en su Dictamen 03/2013, de 19 de diciembre de 2013, considera que los extremos a comprobar en un contrato menor serán, entre otros, la existencia de crédito presupuestario y que el propuesto es el adecuado, que las obligaciones se generan por órgano competente, que el reconocimiento de la obligación responde a un gasto aprobado y la incorporación al expediente de la factura correspondiente que reúna los requisitos reglamentariamente establecidos. Y concluye que la exención de fiscalización previa de los contratos menores alcanza a las fases de autorización y disposición de gasto y, por tanto no se extiende a la fase de reconocimiento de la obligación.

32 Al respecto, Informes de la Junta Consultiva de Contratación Administrativa del Estado número 40/95, 13/96, 30/96, 4/98, 10/98, 12/02, 23/04, 17/05, 38/05.

33 Al respecto, Informe 12/03, de 23 de julio de 2003, de la Junta Consultiva de Contratación Administrativa del Estado.

34 Al respecto, Informes de la Junta Consultiva de Contratación Administrativa del Estado número 29/01, 16/02, 1/09. de 2009

35 En este sentido, el Informe de la Junta Consultiva de Contratación Administrativa del Estado número 1/09, de 25 de septiembre

${ }^{36}$ Al respecto, entre otros, el Informe 2/2009, de 18 de Junio, de la Junta Consultiva de Contratación Administrativa de Murcia; Informe 21/2016, de 27 de abril de 2017, de la Junta Consultiva de Contratación Administrativa del Estado. 
REALA. Nueva Época - N.10, Octubre 2018 - ISSN: 1989-8975 - DOI: 10.24965/reala.v0i10.10557 - [Págs. 56-79]

Análisis de la nueva regulación del contrato menor en la Ley 9/2017, de 8 de noviembre, de Contratos del Sector Público

Roberto Carrodeguas Méndez

bido a las simplificaciones procedimentales inherentes al mismo, pero ello no implica que no sea necesario que el adjudicatario del contrato menor cuente con la debida capacidad de obrar, solvencia y habilitación profesional necesaria para realizar el objeto del contrato.

\subsubsection{Informe del órgano de contratación motivando la necesidad del contrato}

El artículo 28 de la LCSP obliga al órgano de contratación a justificar la necesidad e idoneidad del contrato, sin que puedan celebrarse contratos que no sean necesarios para el cumplimiento y realización de sus fines institucionales. Por ello, la naturaleza y extensión de las necesidades que pretenden cubrirse mediante el contrato proyectado, así como la idoneidad de su objeto y contenido para satisfacerlas, deben ser determinadas con precisión, dejando constancia de ello en la documentación preparatoria.

Se trata, en definitiva, no sólo de garantizar una contratación eficaz, sino también eficiente. De ahí la importancia del informe de necesidad que se debe incorporar preceptivamente al expediente del contrato menor. En los contratos menores se observa, con carácter general, una insuficiente justificación sobre la necesidad e idoneidad del objeto del contrato ${ }^{37}$.

El informe de necesidad del contrato debe ir firmado por el titular del órgano de contratación, sin que pueda sustituirse por un mero acuerdo de inicio ${ }^{38}$.

\subsubsection{Informe del órgano de contratación justificando que no se está alterando el objeto del contrato para evitar la aplicación de las reglas generales de contratación}

El artículo 99.2 de la LCSP dispone que no podrá fraccionarse un contrato con la finalidad de disminuir la cuantía del mismo y eludir así los requisitos de publicidad o los relativos al procedimiento de adjudicación que correspondan.

Debe destacarse que con el fin de fomentar la participación de un mayor número de empresas en la licitación de los contratos públicos, se invierte la regla general vigente hasta ahora, de tal manera que el artículo 99.3 de la LCSP establece que siempre que la naturaleza o el objeto del contrato lo permitan, deberá preverse la realización independiente de cada una de sus partes mediante su división en lotes, teniendo en cuenta que el órgano de contratación podrá no dividir en lotes el objeto del contrato cuando existan motivos válidos, que deberán justificarse debidamente en el expediente, salvo en los casos de contratos de concesión de obras. No obstante, cuando se proceda a la división en lotes, las normas procedimentales y de publicidad que deben aplicarse en la adjudicación de cada lote o prestación diferenciada se determinarán en función del valor acumulado del conjunto, calculado según lo establecido en el artículo 101, salvo que se dé alguna de las excepciones a que se refieren los artículos 20.2, 21.2 y 22.2 (artículo 99.6 de la LCSP).

El fraccionamiento indebido de los contratos utilizando la figura del contrato menor se convirtió en un recurso habitual para evitar la aplicación de los principios básicos de la contratación pública. Como consecuencia de ello, la preocupación por la regulación del fraccionamiento ha sido una constante en la legislación de contratos. Ahora, el legislador para reforzar el control del fraccionamiento indebido, exige al órgano de contratación que incorpore al expediente un informe justificativo sobre este extremo. Una vez más se demuestra que existe una clara desconfianza del legislador hacia el órgano gestor, que se debe en gran medida, tal y como se ha venido indicando a lo largo del presente trabajo, en que el recurso a la adjudicación de contratos menores y al procedimiento negociado sin publicidad hayan sido las dos herramientas de articulación habitual del fraude censurado por el vigente artículo 99.2 de la LCSP.

En efecto, en multitud de ocasiones el fraccionamiento contractual indebido se vincula a la contratación menor. El régimen legal de los contratos menores prevé un supuesto excepcional, cuya tramitación permite al órgano de contratación excepcionar principios como los de libertad de acceso a las licitaciones, de publicidad y de transparencia consagrados en el artículo 1 de la LCSP. Y en este contexto, cobra pleno sentido la afirmación contenida en el Informe 9/2009 de la Junta Consultiva de Contratación Administrativa de Andalucía cuando afirma que «el fraccionamiento del objeto del contrato supone la infracción de normas de ius cogens, que condiciona la validez de los contratos menores a que éstos no excedan de las cuantías

37 Así lo indica, por ejemplo, la Sindicatura de Cuentas de la Comunidad Valencia, Informe de la Cuenta General de la Generalitat correspondiente al ejercicio 2016, de 13 de diciembre de 2017.

38 Así lo ha confirmado la Junta Consultiva de Contratación Administrativa del Estado en el Expediente $42 / 2017$. 
REALA. Nueva Época - N. 10, Octubre 2018 - ISSN: 1989-8975 - DOI: 10.24965/reala.v0i10.10557 - [Págs. 56-79]

Análisis de la nueva regulación del contrato menor en la Ley 9/2017, de 8 de noviembre, de Contratos del Sector Público

Roberto Carrodeguas Méndez

establecidas en el artículo 122.3 de la LCSP. Y es que la utilización del contrato menor sólo es susceptible de una interpretación estricta, vinculada a su correcta calificación y a la exacta apreciación del presupuesto normativo expresamente contemplado y, por tanto, indisponible para el órgano de contratación».

Esta doctrina se fundamenta en la previa del Consejo Consultivo de Andalucía (por todos, Dictamen 106/2000, de 25 de julio, luego seguido, por ejemplo, en el Dictamen 92/2006, de 22 de marzo), incidiendo en la «nulidad de pleno Derecho a que se verían abocados los contratos menores que supongan un fraccionamiento irregular de sus objetos, no busca sino el restablecimiento de la legalidad y tiene, por tanto, una base objetiva, sin que exija una prueba de intencionalidad, pues con ella no se persigue penalizar ninguna conducta y sin que tampoco la especificidad de los productos a suministrar, o un error en el cálculo de las previsiones iniciales para su adquisición, sean causas que permitan el fraccionamiento del objeto del contrato vulnerando lo previsto en el artículo 74.2 de la LCSP, por ello en la duda sobre la concurrencia de los requisitos que hacen posible la conclusión de contratos menores, la Administración ha de reconducir el procedimiento de contratación a las normas generales. Los órganos de contratación han de ser conscientes de la indisponibilidad de las normas rectoras de la contratación pública; regla jurídicamente vinculada a la satisfacción del interés general y que opera como garantía de los principios básicos de publicidad, libre concurrencia y transparencia. Además, los métodos de contratación abierta y competitiva, en los que se aplican adecuadamente los descritos principios, permiten más concurrencia y la obtención de beneficios por ofertas más ventajosas, cuestión esta última que afecta a la eficiente utilización de los recursos públicos en un periodo como el actual, caracterizado por importantes restricciones presupuestarias»

Podemos precisar que un contrato menor es contrario a derecho si el órgano de contratación, en el momento de iniciar la tramitación de este contrato, puede tener conocimiento cierto, aplicando los principios de programación y buena gestión, de la necesidad de contratar una prestación perfectamente definida, cuyas características esenciales no pueden variar, que se tiene que llevar a cabo necesariamente año tras año y que responde a una necesidad continuada en el tiempo, $y$, a pesar de ello se tramita en diferentes contratos menores, eludiendo así las normas de publicidad y procedimiento (Informe 4/2010, JCCA Islas Baleares e Informe de la Intervención General de la Comunidad de Madrid, de 14 de junio de 2013).

La doctrina relativa al fraccionamiento, incide en la existencia o no, de identidad de sujeto, objeto y causa en las distintas prestaciones. Habrá un único contrato cuando haya coincidencia en los elementos sujeto, objeto y causa; sin embargo, habrá que suscribir contratos diferentes cuando la ejecución adecuada de la prestación a realizar motive que uno de estos tres elementos varíe.

En este sentido, considera la Junta Consultiva de Contratación Administrativa de Canarias, en su Informe $1 / 2010$, que «no existirá fraccionamiento fraudulento del objeto contractual cuando, después de haberse realizado un primer contrato, se tenga que volver a contratar con el mismo contratista la misma prestación debido a una necesidad nueva, no previsible en el momento de realizar el primer contrato», ya que en este caso, a pesar de ser el objeto y los sujetos coincidentes, la causa es diferente.

Es indiferente que los contratos presuntamente fraccionados se hayan adjudicado a personas diferentes (Informe 4/2010, Junta Consultiva de Contratación Administrativa de Baleares) y no existirá fraccionamiento irregular, cuando la contratación de varios menores en un único contrato también hubiera podido llevarse a cabo suscribiendo un contrato menor, al no suponer una alteración de las normas de publicidad y de las relativas a los procedimientos de adjudicación (Informe 69/2008, Junta Consultiva de Contratación Administrativa del Estado).

A la hora de emitir el informe justificativo de no alteración del objeto del contrato, el órgano de contratación debería tener en cuenta:

- Que los contratos menores suponen una simplificación sustancial del procedimiento de adjudicación, por lo que su tramitación debe ser restrictiva. Y en todo caso, que no puede celebrarse un contrato menor con el fin de disminuir la cuantía y eludir requisitos de publicidad o los relativos al procedimiento de adjudicación que corresponda.

- Que el contrato menor no es apto para atender las necesidades de carácter recurrente. En la contratación pública, la planificación de las actuaciones que se han de llevar a cabo, se hace imprescindible para determinar el procedimiento contractual adecuado y su falta, puede conllevar un fraccionamiento indebido de los contratos.

- Que el fraccionamiento, para ser conforme a Derecho, no sólo no debe perseguir la evitación de las reglas sobre publicidad y concurrencia, sino que, de forma previa, ha de ser respetuoso con el principio de complitud del objeto del contrato y su necesaria vinculación con las necesidades públicas a satisfacer. 
- Por último, como acertadamente concluye el profesor AGUDO GONZALEZ «el fraude de Ley no es el único límite al fraccionamiento. Los principios de buena administración, de eficacia y eficiencia y de concurrencia también funcionan habitualmente como límites al fraccionamiento del objeto de los contratos. En otras palabras, aun no existiendo un incumplimiento de los principios de publicidad y de las reglas comunes sobre adjudicación de contratos, las exigencias derivadas de aquellos principios pueden vetar el recurso al fraccionamiento» ${ }^{39}$.

\subsubsection{Informe del órgano de contratación justificando que el contratista no ha suscrito más contratos individuales que individual o conjuntamente superen los 40.000 euros en el supuesto de obras o de 15.000 euros cuando se trate de suministro o de servicios}

Podemos afirmar que este nuevo requisito procedimental de incompatibilidad para la adjudicación sucesiva de contratos menores ha sido el que más desconcierto y dudas interpretativas ha generado. La norma tiene un alto grado de indefinición, desde el punto de vista de su aplicación temporal, objetiva y subjetiva. Como advertía CAMPOS ACUÑA «la limitación de que el contratista no haya suscrito más contratos menores que individual o conjuntamente superen la cifra indicada será de las que tendrá mayor impacto. En este sentido, la interpretación de esta limitación será clave para el cumplimiento del objetivo de mejorar la integridad de la contratación» ${ }^{40}$.

En un primer momento, de la lectura del texto legal, un amplio sector doctrinal consideraba que la previsión del artículo 118.3 de la LCSP constituía una limitación por empresario, órgano de contratación y por tipo de contrato. En síntesis, el nuevo artículo 118.3 de la LCSP se convertía en una limitación que impedía poder acumular en favor de una misma empresa uno o varios contratos de obras cuando su valor estimado superase los 40.000 euros o 15.000 euros cuando se trata de contratos de suministro o de servicio.

La justificación de que «el contratista no ha suscrito más contratos menores que individual o conjuntamente superen la cifra que consta en el apartado primero de este artículo», sin indicar a qué contratos menores se refiere encierra importantes dudas interpretativas que no resuelve la literalidad del precepto; todo ello ha motivado, que incluso antes de entrar en vigor la norma, ya se hubiesen emitido informes por las Juntas Consultivas de Contratación Administrativa de Aragón ${ }^{41}$ y del Estado ${ }^{42}$, con el fin dar luz a lo oscuridad interpretativa que encierra el precepto. El goteo de informes de las distintas Juntas Consultivas sobre este tema no deja de crecer. De esta manera, destacamos los recientes Informes de la Juntas Consultivas de Contratación Administrativa de Madrid ${ }^{43}$, Galicia ${ }^{44}$ y Cataluña ${ }^{45}$, así como la Recomendación de la Junta Asesora de Contratación Pública de la Comunidad Autónoma de Euskadi46.

Sin duda alguna, la redacción del precepto presenta graves deficiencias que generan inseguridad jurídica entre los distintos operadores que participan en un contrato, sean sector público o licitadores. Intentaremos, a luz de la doctrina existente, analizar las cuestiones que suscita la limitación prevista en el precepto a nivel subjetivo, objetivo y temporal.

A nivel subjetivo, el precepto no aclara si la regla de incompatibilidad se aplica a las entidades contratantes o bien debe entenderse referida a cada uno de los órganos de contratación que imputan su actuación a una determinada entidad. Pues bien, entendemos que la regla de incompatibilidad resulta de aplicación respecto a los órganos de contratación, ya que el propio precepto se refiere expresamente a que serán éstos

${ }^{39}$ El fraccionamiento de los Contratos: Invalidez y Fraude de ley. Número extraordinario de estudios locales de 2013. Jorge Agudo González.

40 Observatorio de Contratación Pública. 04-12-2017. Concepción Campos Acuña. Novedades de la Ley 9/2017,de Contratos del Sector Público para el ámbito local. http://www.obcp.es/index.php/mod.opiniones/mem.detalle/id.324/chk.084881c8c65e631b4775fbb $7490 d 4 b a 6$.

${ }^{41}$ Informe 3/2018 de la Junta Consultiva Contratación Administrativa de Aragón. Incompatibilidad para la adjudicación de contratos menores.

42 Informes Junta Consultiva Contratación Administrativa del Estado en el expediente 41/2017, 42/2017 y 5/2018.

43 Informe 1/2018, de 11 de abril, sobre adjudicación de los contratos menores en la nueva Ley de Contratos del Sector Público.

44 Informe 1/2018, de 25 de abril de 2018, sobre interpretación del apartado $3 .^{\circ}$ del art. 118 de la Ley 9/2017, de 8 de noviembre de Contratos del Sector Público, a petición de la Diputación de A Coruña.

45 Informe 1/2018, de 20 de abril, de la Junta Consultiva de Contratación Administrativa de la Generalitat de Catalunya (Comisión Permanente). Asunto: Límites a la contratación menor en la Ley 9/2017, de 8 de noviembre, de Contratos del Sector Público.

46 Recomendación 1/2018, de 11 de abril, de la Junta Asesora de Contratación Pública. Destinatarios: Direcciones de Servicios o gestión económica de los departamentos y direcciones de los organismos autónomos. Objeto: Contratos menores a la luz de la nueva Ley de Contratos del Sector Público. 
REALA. Nueva Época - N.10, Octubre 2018 - ISSN: 1989-8975 - DOI: 10.24965/reala.v0i10.10557 - [Págs. 56-79]

Análisis de la nueva regulación del contrato menor en la Ley 9/2017, de 8 de noviembre, de Contratos del Sector Público

Roberto Carrodeguas Méndez

quienes «comprobarán el cumplimiento de la regla de incompatibilidad». Esta posición es defendida en el precitado Informe de la Junta Consultiva de Contratación de Aragón y de Madrid. Por tanto, la adjudicación de contratos menores por parte de un órgano de contratación no impedirá que otros órganos de contratación de la misma entidad contratante adjudiquen contratos al mismo operador económico. Por su parte, como aclara el órgano consultivo gallego, los Informes 41/2017 y 42/2017 de la Junta Consultiva de Contratación Administrativa del Estado relacionan el concepto de órgano de contratación del 118.3 de la LCSP con el artículo 101.6 de la LCSP, pudiendo ser en determinados casos las unidades funcionales separadas con delegación las que le resulte de aplicación de manera autónoma tal limitación.

A nivel objetivo, la redacción del precepto tampoco resulta clara. De esta manera, no precisa si la limitación introducida debe entenderse con independencia del objeto y de las características del contrato.

De conformidad con lo establecido en el artículo 3.1 del Código Civil, «las normas se interpretarán según el sentido propio de sus palabras, en relación con el contexto, los antecedentes históricos y legislativos y la realidad social del tiempo en que han de ser aplicadas, atendiendo fundamentalmente al espíritu y finalidad de aquellas». Teniendo en cuenta lo indicado, consideramos que de una interpretación literal y teológica del precepto debe concluirse que la regla de incompatibilidad legal ex artículo 118.3 de la LCSP impide celebrar contratos de un mismo tipo con el mismo contratista.

Esta posición es la más coherente con el tenor literal del precepto, ya que al utilizar el legislador la conjunción copulativa «y», obliga a verificar, por una parte, que se cumple la regla de la prohibición general de fraccionamiento de los contratos, proscrita por el artículo 99.2 de la LCSP, que debe ser objeto de comprobación por el órgano de contratación (... En el expediente se justificará que no se está alterando el objeto del contrato para evitar la aplicación de las reglas generales de contratación) y por otra parte, que no se supera un determinado importe de contratación (... y que el contratista no ha suscrito más contratos menores...).

Esta interpretación también es la más razonable desde el punto de vista teológico y sistemático de la norma, pues parece que en todo momento la intención del legislador es limitar la contratación directa, impulsando los principios de igualdad, transparencia y libre concurrencia mediante la articulación de un procedimiento de licitación simplificado abreviado que servirá para sustituir a la contratación directa en los supuestos en que las necesidades a contratar presenten carácter repetitivo.

A mayor abundamiento, debemos recordar que este precepto tiene su antecedente directo en la Proposición de Ley sobre transparencia y lucha contra la corrupción presentada en el año 2012 por el Grupo Parlamentario de Unión Progreso y Democracia ${ }^{47}$ que establecía que ninguna empresa podría ser adjudicataria durante un mismo ejercicio presupuestario de un número de contratos menores de cualquier clase celebrado con un mismo organismo cuya cuantía acumulada superase los 50.000 euros. Esta Proposición fue rechazada por el Congreso de los Diputados pero inspiró la redacción de la Ley Foral 14/2014, de 18 de junio, que modificó la Ley Foral 6/2006, de 9 de junio, de Contratos Públicos de Navarra, dando una nueva redacción al artículo 73, al establecer en su apartado 6 que «ninguna empresa o profesional podrán ser adjudicatarios dentro de la misma administración contratante y durante un mismo ejercicio presupuestario de un número de contratos adjudicados mediante factura o factura con reserva de crédito cuya cuantía acumulada sea superior a 80.000 euros, IVA excluido, en obras, y 30.000 euros, IVA excluido, en el resto de contratos» ${ }^{48}$.

Esta ha sido la posición defendida en los Informes emitidos por la Juntas Consultivas de Contratación Administrativa de Aragón, Madrid y Euskadi, que concluyen que el texto legal introduce una limitación que impide adjudicar de manera sucesiva contratos de una misma tipología -obras, servicios y suministros- con independencia de su objeto y características.

Frente a este posición, las Juntas Consultivas de Contratación Administrativa del Estado, Galicia y Cataluña consideran que la Ley no contempla una limitación a la celebración de contratos menores con un mismo operador económico cuando las prestaciones objeto de los mismos sean cualitativamente diferentes y no formen una unidad. Fuera de estos casos, si sería posible celebrar otros contratos menores con el mismo contratista. Interpretación esta última que no compartimos con fundamento en los argumentos jurídicos anteriormente reproducidos.

A nivel temporal, consideramos que la prohibición de no superar las cuantías del contrato menor con un mismo empresario ha de entenderse referida a la anualidad o ejercicio presupuestario correspondiente. Esta posición es la defendida por las diferentes Juntas Consultivas de Contratación Administrativa, a excepción

47 Boletín Oficial de las Cortes Generales, núm. 36-1, de 5 de enero de 2012, artículo 5. Medidas contra la corrupción en la contratación administrativa.

48 Como curiosidad indicar que la nueva Ley Foral 2/2018, de 3 de abril, de Contratos Públicos, no contempla esta limitación. 
de la del Estado, que sostiene en su Informe 5/2018 que la limitación del precepto debe entenderse de fecha a fecha, identificando este plazo con la duración máxima de los contratos menores prevista en el artículo 29.8 de la LCSP, a saber, un año. Plazo este último que se contaría a partir de la aprobación del gasto. Consideramos que esta interpretación no resulta sostenible, tanto desde el punto de vista de los trabajos parlamentarios y de los antecedentes jurídicos de la norma ${ }^{49}$ como del criterio de anualidad en la programación de la contratación y control presupuestario ${ }^{50}$.

Como se ha indicado, la interpretación dada al precepto por la Junta Consultiva de Contratación Administrativa del Estado -Informes JCAE 41/2017, 42/2017 y 5/2018- difiere de la efectuada por el órgano consultivo de Aragón -Informe 3/2018- con relación al ámbito objetivo y temporal de la limitación que impone el artículo 118.3 de la LCSP, agudizando la complejidad que encierra por si sola la aplicación práctica del precepto. Dificultad interpretativa que se ha visto acrecentada por los Informes posteriores de otros órganos consultivos. Con el fin de unificar criterios y dar una solución al operador jurídico, sobre la base de esta interpretación contradictoria, se ha creado la Comisión Bilateral de Cooperación Aragón-Estado, que tiene por finalidad iniciar negociaciones para resolver las discrepancias manifestadas por la LCSP. Sin perjuicio del mayor o menor acierto de los informes emitidos por los órganos consultivos de contratación, podríamos concluir indicando, que lo que a día de hoy resulta evidente, es que el artículo 118.3 de la LCSP presenta graves deficiencias en su redacción, que exigen una urgente interpretación clarificatoria de sus términos y contenido, en la medida en que provoca un alto grado de inseguridad jurídica en los distintos agentes que intervienen en el contrato, sean sector público o licitadores.

\subsubsection{Perfección del contrato menor}

El artículo 36.1 de la LCSP dispone que los contratos que celebren los poderes adjudicadores, a excepción de los contratos menores y de los contratos basados en un acuerdo marco y los contratos específicos en el marco de un sistema dinámico de adquisición a los que se refiere el apartado 3 de este artículo, se perfeccionan con su formalización. Por otra parte, el artículo 153 de la LCSP dedicado a la formalización de los contratos, establece en su apartado 2 que «en el caso de los contratos menores definidos en el artículo 118 se acreditará su existencia con los documentos a los que se refiere dicho artículo».

Por otra parte, sigue vigente el artículo 72.1 del Real Decreto 1098/2001, de 12 de octubre, por el que se aprueba el Reglamento general de la Ley de Contratos de las Administraciones Públicas (RGLCAP), que dispone que en los contratos menores podrá hacer las veces de documento contractual la factura pertinente, que deberá contener los datos y requisitos establecidos en el Real Decreto 2402/1985, de 18 de diciembre, por el que se regula el deber de expedir y entregar factura que incumbe a los empresarios y profesionales (a fecha actual, Real Decreto 1619/2012, de 30 de noviembre, por el que se aprueba el Reglamento por el que se regulan las obligaciones de facturación).

Por motivos de agilidad y simplificación del procedimiento no resulta preceptivo que los derechos y obligaciones de las partes se especifican en un documento escrito. En este aspecto, la LCSP introduce un matiz importante con respecto a la legislación anterior en el que la factura expedida por el contratista se convertía en esencial en la medida que servía de documento contractual ${ }^{51}$.

La Ley no se refiere ahora a la formalización, sino a la acreditación de la existencia del contrato menor por alguno de los documentos del artículo 118 de la LCSP. La redacción del precepto vuelve a generar confusión en el operador jurídico, ya que podríamos llegar a entender que existe el contrato menor desde el momento en que se firma el informe de necesidad del contrato o se aprueba el gasto, sin existir un tercero en el que haya recaído la adjudicación; cuestión esta última que, a todas luces, no se puede sostener atendiendo a la definición del contrato recogida en el artículo 1254 de nuestro Código Civil.

49 En este sentido, recordar que la adición de un apartado 3 al artículo 118 del Proyecto de Ley de Contratos del Sector Público presentado por el Gobierno trae causa de la enmienda 583 presentada por el Grupo Parlamentario Socialista en el Congreso de los Diputados, que decía textualmente: «En el expediente se garantizará que no se está alterando el objeto del contrato para evitar la aplicación de las reglas generales de la contratación, y el contratista no haya suscrito más contratos menores en la misma anualidad, lo que comprobará del responsable del contrato»

50 Al respecto, el artículo 28.4 de la LCSP dispone que las entidades del sector público programarán la actividad de contratación pública, que desarrollarán en un ejercicio presupuestario o períodos plurianuales y darán a conocer su plan de contratación anticipadamente mediante un anuncio de información previa previsto en el artículo 134 que al menos recoja aquellos contratos que quedarán sujetos a una regulación armonizada.

51 Al respecto, Informe 34/2010, de 6 de abril de 2011, de la Junta Consultiva de Contratación Administrativa del Estado. 


\subsubsection{Ejecución del contrato menor}

Una vez adjudicado el contrato, se iniciará la ejecución de las actuaciones correspondientes, que generalmente consistirán en ejecutar una obra, realizar un suministro o prestar un servicio.

Fuera de los rasgos característicos que definen su adjudicación, el contrato menor no presenta más singularidades respecto a su configuración normativa. A tal efecto, dentro de los límites y con sujeción a los requisitos y efectos señalados en la LCSP, el órgano de contratación ostentará la prerrogativa de interpretar los contratos, resolver las dudas que ofrezca su cumplimiento, modificarlos por razones de interés público, declarar la responsabilidad imputable al contratista a raíz de la ejecución del contrato, suspender la ejecución del mismo, acordar su resolución y determinar los efectos de esta (artículo 190 LCSP).

En efecto, los contratos menores pueden ser objeto de modificación y resolución, cuando concurran las circunstancias previstas en la LCSP que habiliten la misma. Con relación a su modificación, el único problema que se podría plantear sería el riesgo de que un contrato que no ha sido objeto de publicidad pueda, a través del mecanismo de la modificación contractual, exceder de estos límites máximos y requerir, de un procedimiento distinto. En este supuesto, no deberíamos tramitar un nuevo contrato menor, ya que podríamos incurrir en un fraccionamiento del contrato, al eludir los requisitos de publicidad, procedimiento y forma de adjudicación que correspondan ${ }^{52}$.

\subsubsection{Necesidad de dar publicidad a los contratos menores}

El artículo 118.4 y el artículo 154.5 de la LCSP introducen un nuevo requisito en la tramitación del expediente del contrato menor, al exigir su publicación en la forma prevista en el artículo 63.4 de la LCSP. Dicho precepto establece que la publicación de la información relativa a los contratos menores deberá realizarse al menos trimestralmente. La información a publicar para este tipo de contratos será, al menos, su objeto, duración, el importe de adjudicación, incluido el Impuesto sobre el Valor Añadido, y la identidad del adjudicatario, ordenándose los contratos por la identidad del adjudicatario.

La LCSP exceptúa la publicación de aquellos contratos cuyo valor estimado fuera inferior a cinco mil euros, siempre que el sistema de pago utilizado por los poderes adjudicadores fuera el de anticipo de caja fija u otro sistema similar para realizar pagos menores.

Antes de la aprobación de la nueva LCSP, la Ley 19/2013, de 9 de diciembre, de transparencia, acceso a la información pública y buen gobierno (LTBG) ya regulaba en su artículo 8.1 a) la publicidad relativa a los contratos de todos los sujetos obligados por esta norma. El preceptos señala «que todos los contratos, con indicación del objeto, duración, el importe de licitación y de adjudicación, el procedimiento utilizado para su celebración, los instrumentos a través de los que, en su caso, se ha publicitado, el número de licitadores participantes en el procedimiento y la identidad del adjudicatario, así como las modificaciones del contrato. Igualmente serán objeto de publicación las decisiones de desistimiento y renuncia de los contratos. La publicación de la información relativa a los contratos menores podrá realizarse trimestralmente».

EI TRLCSP establecía determinadas obligaciones acerca de la publicidad de los contratos del Sector Público, que eran de aplicación a los contratos menores. Las obligaciones con respecto a la publicidad de los contratos públicos que emanan de la legislación sobre transparencia son complementarias y, en el caso de los contratos menores, más amplias que las que establecía la legislación sobre contratación pública.

\subsubsection{Comunicación al Registro Oficial de Contratos del Sector Público y al Tribunal de Cuentas de los contratos menores realizados}

El artículo 346 de la LCSP exige que los poderes adjudicadores comunicarán al Registro de Contratos del Sector Público, para su inscripción, los datos básicos de los contratos por ellos adjudicados, entre los que figurará la identidad del adjudicatario, el importe de adjudicación de los mismos, junto con el desglose correspondiente del Impuesto sobre el Valor Añadido. Igualmente comunicarán, en su caso, las modificaciones, prórrogas, variaciones de plazos o de precio, importe final y extinción de aquellos. El contenido y el formato de dichas comunicaciones, así como el plazo para efectuarlas, se establecerán reglamentariamente.

52 Así lo ha señalado el Informe 4/2001, de 4 de abril, de la JCCA de la Comunidad de Madrid, que versa, precisamente sobre la modificación contractual de los contratos menores. 
REALA. Nueva Época - N.10, Octubre 2018 - ISSN: 1989-8975 - DOI: 10.24965/reala.v0i10.10557 - [Págs. 56-79]

Análisis de la nueva regulación del contrato menor en la Ley 9/2017, de 8 de noviembre, de Contratos del Sector Público

Roberto Carrodeguas Méndez

Se exceptuarán de esta comunicación los contratos excluidos por la LCSP y aquellos cuyo precio fuera inferior a cinco mil euros, IVA incluido, siempre que el sistema de pago utilizado por los poderes adjudicadores fuera el de anticipo de caja fija u otro sistema similar para realizar pagos menores.

En el resto de contratos inferiores a cinco mil euros, deberá comunicarse el órgano de contratación, denominación u objeto del contrato, adjudicatario, número o código identificativo del contrato e importe final.

Del mismo modo, el artículo 335.1 de la LCSP exige la remisión al Tribunal de Cuentas de una relación de los contratos menores celebrados, excepto aquellos que siendo su importe inferior a cinco mil euros se satisfagan a través del sistema de anticipo de caja fija u otro sistema similar para realizar pagos menores, donde se consignará la identidad del adjudicatario, el objeto del contrato y su cuantía.

Como observamos, los requisitos de publicidad y control se flexibilizan para aquellos contratos de escasa cuantía cuyo pago se efectúe mediante un sistema de anticipo de caja fija o instrumento similar.

\section{3. ¿Aplicación del artículo 118 de la lcsp a todos los poderes adjudicadores?}

El Libro III de la LCSP establece el régimen jurídico de los contratos celebrados por los PANAPs. La principal novedad de la nueva regulación es la supresión de las instrucciones de contratación, así como del resto de entes del sector público que no tengan el carácter de poderes adjudicadores, estableciéndose claramente la regulación que les resulta aplicable. En efecto, se establecen las mismas normas de preparación y adjudicación para todos los contratos armonizados, con independencia de que el poder adjudicador tenga o no el carácter de Administración Pública (artículo 317 LCSP); así como la desaparición total de las instrucciones internas en la adjudicación de los contratos no armonizados de poderes adjudicadores no Administración Pública (artículo 318 LCSP) y parcial en el caso de los entes del sector público que no son poder adjudicador (art. 321 LCSP).

El artículo 318, dedicado a la adjudicación de los contratos no sujetos a regulación armonizada, dispone en la letra a) que los contratos de valor estimado inferior a 40.000 euros, cuando se trate de contratos de obras, de concesiones de obras y concesiones de servicios, o a 15.000 euros, cuando se trate de contratos de servicios y suministros, podrán adjudicarse directamente a cualquier empresario con capacidad de obrar y que cuente con la habilitación profesional necesaria para realizar la prestación objeto del contrato.

Un importe sector doctrinal planteó que la regulación prevista en el artículo 118 y 131.3 de la LCSP no era de aplicación a los PANAPs en la medida que el artículo 318.a) no emplea nominatim el término de «contratos menores», y tampoco contiene una remisión expresa a los precitados artículos. Así, tras la aprobación de la nueva Ley, DIEZ SASTRE se cuestionaba la aplicación del régimen jurídico del contrato menor a los PANAPs afirmando que «...el legislador reserva cuidadosamente la utilización del concepto de contrato menor para los casos en que contrata una Administración Pública. Si la entidad adjudicadora no es Administración Pública, no se habla en ningún momento de contrato menor, simplemente se prevé la adjudicación directa con otros requisitos y con límites mucho más amplios. Este detalle no es baladí. Es cierto que los umbrales económicos son los mismos que los propios del contrato menor, pero esa es la única coincidencia. El contrato menor es un tipo de contrato que se reserva para las Administraciones Públicas. En el resto de casos el legislador establece los requisitos aplicables para adjudicar los contratos de cuantías equivalentes a las del contrato menor. La respuesta a la pregunta planteada en el título de esta reflexión es, por tanto, negativa. No hay una unificación del régimen jurídico aplicable al contrato menor para todos los entes del sector público» ${ }^{53}$.

No obstante, no ha sido esta la posición de defendida por la Abogacía del Estado en el Informe 2/2018 Aprecia la Abogacía fundamento jurídico para concluir que la concreta mención del artículo 318 a) a los contratos de valor estimado inferior a 40.000 , en el caso de contratos de obras, concesiones de obras y concesiones de servicios, y a 15.000 euros, en caso de contratos de servicios y suministros (importes plenamente coincidentes con los previstos para los contratos menores en el artículo 118.1 de la LCSP), unida a la previsión de que los mismos «podrán adjudicarse directamente a cualquier empresario con capacidad de obrar y que cuente con la habilitación profesional necesaria para realizar la prestación objeto del contrato» (expresión idéntica a la empleada por el legislador en el artículo 131.3 de la LCSP para aludir a los contratos menores), no es una mera casualidad o coincidencia, sino una decisión deliberada del legislador, que está configurando un supuesto conceptualmente coincidente con los contratos menores.

53 Blog Oficial del Instituto de Derecho Local de la UAM. “¿El nuevo régimen jurídico de los contratos menores se aplica a todos los entes del sector público?", Silvia DÍEZ SASTRE, 17 de noviembre de 2017, http://www.idluam.org/blog/?p=490.

54 Informe Abogacía del Estado 2/2018, 17 de enero de 2018. Ref: AG entes públicos 2/2012 (R-32/2018). 
Concluye la Abogacía del Estado que dado que los contratos a los que se refiere el artículo 318 a) de la LCSP son conceptualmente coincidentes con los contratos menores, no se advierte razón legal que excluya la aplicación a estos contratos de los requisitos que, con carácter general, establece para los contratos menores el artículo 118 de la LCSP. El artículo 118 de la LCSP contiene, en aras de la seguridad jurídica, las reglas aplicables a la tramitación del expediente de contratación en los contratos menores, e incorpora ciertas cautelas tendentes a evitar su uso abusivo y fraudulento, previsiones, todas ellas, que parece lógico considerar aplicables a los contratos menores que celebren los poderes adjudicadores que no tengan la condición de Administraciones Públicas, habida cuenta que el objetivo de la Ley es, como declara su Preámbulo «diseñar un sistema de contratación pública más eficiente, transparente e íntegro», "persiguiéndose en todo momento la eficiencia en el gasto público y el respeto a los principios de igualdad de trato, no discriminación, transparencia, proporcionalidad e integridad».

Consideramos que la interpretación efectuada por la Abogacía del Estado responde más a un deseo que a una exigencia que se derive del texto legal. Es cierto que la LCSP trata de homogeneizar el régimen de las Administraciones Públicas y de los PANAP, pero también contempla regulaciones de procedimiento diferenciadas y sistemáticamente separadas. Así, para los PANAPs el artículo 318 a) no utiliza expresamente el término "contratos menores»; su objeto es diferente (incluye concesiones de obras y de servicios); el artículo 318 es una norma de adjudicación, a diferencia del artículo 118 que es una norma de preparación; el artículo 318 a) no contiene ninguna referencia o remisión expresa que permita llegar a la conclusión de que la intención del legislador es aplicar los requisitos del artículo 118 a los contratos que por esa cuantía celebren los PANAPs; la letra b) del artículo 318 determina que para los contratos de cuantía superior a la letra a) no sujetos a regulación armonizada resulta de aplicación la normas de adjudicación de los contratos de las Administraciones Públicas, implícitamente está reconociendo que para los anteriormente citados su régimen es diferente; por último, el tenor literal del artículo 321.2 a) -adjudicación de contratos del sector público que no tienen el carácter de poderes adjudicadores- es idéntico al artículo 318 a), lo que confirma que el artículo 118 se aplica exclusivamente a la preparación de los contratos menores de las Administraciones Públicas.

Atendiendo a los argumentos jurídicos expuestos, podríamos llegar a concluir que los contratos adjudicados directamente por los PANAPs no están sometidos al límite temporal de un año, pudiendo ser objeto de prórroga, en la medida en que el artículo 29.8 de la LCSP únicamente prevé estas limitaciones temporales para los contratos menores descritos en el artículo 118.

\subsection{Algunas cuestiones prácticas}

Los poderes adjudicadores acuden al mercado para satisfacer los fines de interés público que tienen encomendados cuando no pueden hacerlo con sus propios medios. Son muchas las ocasiones en la que la contratación pública no se puede planificar, debiendo contratarse con celeridad y urgencia, provocando que el procedimiento de adjudicación -diferente del contrato menor-, por sus trámites y plazos, pueda convertir el contrato en estéril e ineficaz.

El contrato menor pasa a configurarse como una categoría residual fruto de la nueva regulación restrictiva dada por el legislador. Como alternativa más significativa a la contratación directa, la LCSP plantea la posibilidad de utilizar para contratar un procedimiento abierto simplificado abreviado que se regula en el artículo 159.6 LCSP $^{55}$. Este procedimiento, llamado a convertirse en el sustituto del procedimiento negociado sin publicidad, permitirá canalizar contratos que hasta la fecha se venían celebrando como contratos menores.

No obstante, llegado este momento, cabe cuestionarse si las Administraciones Públicas, y en especial, la Administración local, están capacitadas para afrontar este cambio en su modelo de contratación. No parece lógico, ni mucho menos operativo establecer el mismo régimen jurídico de contratación directa para todos los poderes adjudicadores sin tener en consideración la organización, presupuesto y tamaño de las entidades.

${ }^{55}$ Este procedimiento, que se puede utilizar adjudicar los contratos de obras de valor estimado inferior a $80.000 €$ y en los contratos públicos de suministro y de servicios de valor estimado inferior a $35.000 €$, se caracteriza por la rapidez y sencillez de sus trámites. Así, el plazo para la presentación de proposiciones será como mínimo de 10 días hábiles desde el siguiente a la publicación del anuncio de licitación, reduciéndose a 5 días en compras corrientes de bienes disponibles en el mercado. Todos los criterios de adjudicación que deben utilizarse serán automáticos -aplicación de fórmulas establecidas en los pliegos- por lo que no caben los criterios de juicio de valor, no debe acreditarse la solvencia económica, financiera ni técnica y profesional, la constitución de la mesa de contratación es facultativa, se debe garantizar el libre acceso y sin restricción a las ofertas y a la documentación sobre su valoración, desde la notificación de la adjudicación del contrato, la formalización del contrato consistirá en la firma de la aceptación que pondrá el contratista en la resolución de adjudicación del contrato y desaparece la garantía definitiva. 
En este sentido, es preciso destacar que de los 8.124 municipios existentes en España, a fecha 1 de enero de 2018, 1.364 tienen menos de 100 habitantes, 4.998 menos de 1.000 habitantes y 2.371 menos de 10.000 habitantes $^{56}$. Exigir un auténtico expediente en el que deberán recogerse una serie de justificaciones, que van más allá de la simple factura del proveedor que hasta ahora se venía aportando para los contratos de escasa cuantía y duración, puede provocar el retraso y paralización de la activad contractual de muchos Ayuntamientos, con el riesgo de que el artículo 118 de la LCSP se convierta en papel mojado. No por falta de voluntad de técnicos o responsables políticos, sino por una cuestión de operatividad y de medios personales y materiales existentes en este tipo de organizaciones.

Por todo ello, no parece adecuado diseñar el mismo expediente para los municipios de gran población que para aquellos otros que apenas alcanzan el centenar de habitantes. Recordemos, en este sentido, como el derogado artículo 88.3 de la Ley 7/1985, de 2 de abril, Reguladora de las Bases del Régimen Local, regulaba la contratación directa en función de los recursos ordinarios de la entidad.

Tampoco parece proporcional que deba tramitarse el mismo expediente para el suministro de un lápiz de $0,50 €$ que para contratar una obra de $39.999,99 €$; incluso no admitir la posibilidad de celebrar un contrato menor para determinados servicios o suministros de exigua cuantía, por el mero hecho de que se repita en el tiempo la necesidad, debiendo licitarse, por ejemplo, la compra diaria de un periódico de 1,00€.

Por otra parte, la LCSP proyecta a nuestro ordenamiento interno las soluciones propuestas en el "Código europeo de buenas prácticas para facilitar el acceso de las pymes a los contratos públicos» (Comisión 2506-2008) y en la Directiva 2014/24/UE, tendentes a facilitar la participación de las PYMES en las licitaciones públicas, introduciendo un conjunto de medidas que persiguen facilitar su acceso a la contratación pública, potenciando la contratación electrónica.

En el conjunto de medidas que articula la LCSP, no compartimos los pretendidos efectos positivos de incremento de la participación en la contratación pública de pymes, micropymes y autónomos que pretende impulsar la nueva regulación del contrato menor. Precisamente han sido estas últimas quienes de manera recurrente han venido ejecutando prestaciones de escasa cuantía y duración en el municipio en el cual se encontraban instaladas a través de esta figura contractual, dinamizando la Administración la economía local vía contrato menor.

Al mismo tiempo, desconocemos si los pequeños proveedores de la Administración están preparados para adaptarse a los nuevos retos que exige la contratación electrónica. Esta última herramienta conlleva importantes ventajas, pero exige el uso e integración de las tecnologías en los procesos de gestión empresarial, así como una base sólida de conocimiento tecnológico y formación continua en competencias digitales básicas. Puede darse el efecto perverso que, ante contratos poco atractivos desde el punto de vista económico, el hecho de prescindir del contrato menor y exigirle al contratista participar en un procedimiento de licitación electrónico provoque la falta de respuesta inmediata del mercado, y en consecuencia, determinadas necesidades urgentes de la Administración no puedan ser atendidas.

\section{A MODO DE REFLEXIÓN FINAL}

Como se ha tratado de exponer, la aplicación del nuevo régimen jurídico de lo que se viene denominando contratación menor encierra una enorme complejidad. La redacción desafortunada dada por el legislador al artículo 118 LCSP dificulta enormemente la espinosa tarea de aplicar las nuevas limitaciones que contempla el precepto. Los Informes contradictorios emitidos por las distintas Juntas Consultivas de Contratación Administrativa en esta materia agudizan la enorme inseguridad jurídica en la que se mueven los operadores jurídicos.

Por todo ello, es un hecho innegable que el cambio legislativo operado puede provocar un bloqueo en el funcionamiento de la Administración. Tal y como se ha apuntado, la finalidad del contrato menor es posibilitar una rápida satisfacción a las necesidades de la Administración que, por su escasa cuantía y duración temporal, puedan adjudicarse de manera directa a cualquier empresario con capacidad de obrar y que cuente con la habilitación profesional necesaria para realizar la prestación, a través de un procedimiento sencillo y ágil, en el que se excepcionen los principios de publicidad y concurrencia.

Es posible afirmar que, en el ámbito de la Administración Local, una buena utilización del contrato menor puede convertirse en una herramienta útil para este tipo de organizaciones administrativas, atendiendo a su tamaño y a sus medios, y sobre todo, a sus necesidades de contratación.

\footnotetext{
56 Datos del CIS -Abril 2018-.
} 
Uno de los objetivos perseguidos con este trabajo ha sido reflexionar sobre si la mala fama que persigue al contrato menor se debe a cuestión de procedimiento o a la forma de utilizarlo. Vincular el contrato menor con la corrupción y la falta de integridad en la contratación pública es algo demagógico. Decir que su regulación atenta al Derecho de la Unión también. Únicamente su mala utilización mediante el fraccionamiento ilícito del objeto del contrato, así como su uso repetitivo y abusivo puede llegar a justificar una regulación tan restrictiva como la que ahora plantea el legislador.

Debemos abandonar la arraigada idea de que la celebración de un contrato menor por el poder adjudicador comporta siempre una actuación ineficiente. Si se utiliza correctamente, la contratación directa sirve en determinadas ocasiones como instrumento oportuno para el adecuado funcionamiento de la Administración; en la medida en que el fin último de toda actuación administrativa es la satisfacción de un interés público, puede resultar de enorme utilidad para dar una respuesta inmediata a las necesidades que surgen en el quehacer diario de las Administraciones.

A lo expuesto, debe sumarse que una buena estrategia de compra pública a través del contrato menor puede resultar beneficiosa para fomentar la participación de autónomos y de micropymes locales en la contratación con la Administración local, al beneficiarse directamente de contratos públicos del Ayuntamiento en cuyo término municipal se encuentran instaladas, favoreciendo su crecimiento empresarial y la creación de empleo. No han sido pocas las ocasiones en las que la celebración de contratos menores se han convertido en el principal aliado para garantizar la supervivencia de las pymes locales, en la medida en que su utilización permite la simplificación de trámites, reducción de la burocracia y eliminación de la competencia de los grandes grupos empresariales, consiguiendo repartir prestaciones y trabajos de escasa cuantía entre los pequeños proveedores instalados en un determinado ámbito territorial.

No cabe duda que la nueva Ley podría haber mejorado la regulación jurídica de la contratación directa que ofrecía el Texto Refundido de la Ley de Contratos del Sector Público (petición de ofertas, registro municipal de empresas, mayor publicidad...). En este sentido, podemos indicar que el legislador ha perdido una gran oportunidad.

De esta manera, consideramos necesaria una reforma urgente de la LCSP que permita dotar de una mayor flexibilidad a la contratación directa en el ámbito de las entidades locales. En este sentido, resulta de interés la solución propuesta por el Observatorio de Contratación Pública para facilitar la contratación en proyectos de $1+D+i^{57}$. A nuestro juicio, nada impediría que el procedimiento descrito para la adquisición de suministros y servicios por Organismos Públicos de Investigación en la gestión de proyectos de investigación, desarrollo e innovación tecnológica o servicios técnicos pudiese ser aplicado en los ayuntamientos, especialmente en los más pequeños, evitando la ralentización de los procesos de contratación. Con esta modificación se superaría la limitación excesiva de la adquisición directa de suministros y servicios, permitiendo, entre otros aspectos, que la prestaciones de importe inferior a los 1.000 euros, en cuanto gasto menor, se pudiesen justificar con la presentación de una simple factura electrónica.

Frente a la opinión mayoritaria de la doctrina, entendemos que erradicar y limitar la utilización de la contratación directa puede suponer una paralización y retraso injustificado en el funcionamiento de la Administración, y en especial, de los gobiernos locales. Mientras no se modifique la actual planta municipal española, caracterizada por la presencia de municipios pequeños y de escasa población, o bien se profesionalice y dote de medios técnicos y materiales a muchos de los Ayuntamientos de nuestro país, será muy difícil, por no decir imposible, desterrar la contratación menor.

Por todo ello, el contrato menor sigue siendo un «contrato necesario». Prescindir de su utilización se antoja complicado. Solo el tiempo y la experiencia lo confirmarán.

\section{BIBLIOGRAFÍA}

AGUDO GONZALEZ, J. (2013): "El fraccionamiento de los contratos: invalidez y fraude de ley", en Revista de Estudios Locales (CUNAL), núm. 161, págs. 147-181.

ARROYO DIEZ, A. (2018): "La adjudicación de los contratos no armonizados por los poderes adjudicadores no administración pública en la nueva Ley de Contratos del Sector Público", en Revista Aranzadi Doctrinal, núm. 2, págs. 29-35.

57 Contratación pública en proyectos de I+D+i. Propuesta del Observatorio de Contratos Públicos para su regulación mediante un procedimiento específico. Propuesta de modificaciones de la Ley 9/2017, de Contratos del Sector Público, por el que se transponen al ordenamiento jurídico español las Directivas del Parlamento Europeo y del Consejo, 2014/23/UE y 2014/24/UE, de 26 de febrero de 2014. http://obcp.es/index.php/mod.noticias/mem.detalle/id.1320/relmenu.2/chk.a3ba2458eb4a50645389bcfa76574004. 
REALA. Nueva Época - N. 10, Octubre 2018 - ISSN: 1989-8975 - DOI: 10.24965/reala.v0i10.10557 - [Págs. 56-79]

Análisis de la nueva regulación del contrato menor en la Ley 9/2017, de 8 de noviembre, de Contratos del Sector Público

Roberto Carrodeguas Méndez

BALLESTEROS MOFFA, L. A., BATET JIMENEZ, P., BELLO PAREDES, S. A., BERNAL BLAY, M. A. Y OTROS (2018): Contratación del sector público local, LA LEY: Grupo Wolters Kluwer, 4. ${ }^{a}$ edición.

BLAZQUEZ LIDOY, A. (2018): "Los poderes adjudicadores no Administración pública ante la Ley de contratos del sector público (Ley 9/2017): contratos menores y libertad en los procedimientos de adjudicación", en Revista CEFLegal: revista práctica de derecho. Comentarios y casos prácticos, núm. 208, págs. 93-120.

CANDELA TALAVERO, J. E. (2011): "El fraccionamiento del objeto de los contratos públicos y la fraudulenta utilización del contrato menor", en Auditoría Pública: revista de los Órganos Autónomos de Control Externo, núm. 53, págs. 85-94.

DELGADO FERNANDEZ, M. R. (2017): "La gestión de los contratos de pequeña cuantía según la nueva normativa de contratación pública. Contratos menores, sistemas dinámicos de adquisición y procedimiento abierto simplificado de tramitación sumaria", en Gabilex: Revista del Gabinete Jurídico de Castilla-La Mancha, núm. 12, págs. 15-49.

DE SOLAS RAFECAS, J. M. (1996): "Los procedimientos de selección de contratistas y de adjudicación de los contratos de la Administración, y en especial del contrato de obras públicas, en el Proyecto de Ley de Contratos de la Administraciones Públicas", dentro de las Jornadas sobre Contratación Pública organizadas por la Universidad de Valladolid en 1993. Madrid: Marcial Pons-Cámara de Contratistas de Castilla y León, pág. 86.

ESCRIHUELA MORALES, F. J. (2018): "La contratación del sector público. Especial referencia a los contratos de suministro y servicios", en Manuales Profesionales LA LEY: Grupo Wolters Kluwer, 5. ${ }^{a}$ edición.

GALLEGO CORCOLES, I. (2018): "El procedimiento abierto simplificado y el procedimiento simplificadísimo", en Contratación administrativa práctica: revista de la contratación administrativa y de los contratistas, núm. 153, págs. 104-113.

GARCIA HERNANDEZ, J. (2016): "El fraccionamiento de los contratos menores y su no fiscalización: consecuencias penales", en Revista de Derecho Local, núm. 44.

GIMENO FELIU, J. M. (2016): "La corrupción en la contratación pública. Propuestas para rearmar un modelo desde la perspectiva de la integridad", en La corrupción en España. Ámbitos, causas y remedios jurídicos, Barcelona: Atelier, págs. 246-300.

GIMENO FELIU, J. M. (2010): "La Ley de Contratos del Sector Público: ¿una herramienta eficaz para garantizar la integridad? Mecanismos de control de la corrupción en la contratación pública", en REDA, núm. 147, págs. 517-535.

GIMENO FELIU, J. M. (2013): "Las nuevas Directivas -cuarta generación- en materia de contratación pública. Hacia una estrategia eficiente en compra pública", en REDA, núm. 159, págs. 25-89.

GIMENO FELIU, J. M. (2017): "Hacia una nueva Ley de Contratos del Sector Público. ¿Una nueva oportunidad perdida?", en REDA, núm. 182, págs. 181-221.

GIMENO FELIU, J. M. (2016): "Transparencia y prevención de la corrupción en materia de contratación pública y su modelo de control", en Revista de Estudios Locales (CUNAL), núm. 195, págs. 10-20.

GIMENO FELIU, J. M. (2016): "El necesario big-ban contra la corrupción en materia de contratación pública y su modelo de control", en Revista internacional de transparencia e integridad, núm. 2.

GIMENO FELIU, J. M. (2018): "La nueva Ley de Contratos del Sector Público: hacia un modelo de contratación pública transparente", en Contratación Administrativa Práctica: revista de la contratación administrativa y de los contratistas, núm. 153, págs. 34-39.

GIMENO FELIU, J. M. (2018): "La nueva regulación de la contratación pública en España desde la óptica de la incorporación de las exigencias europeas: hacia un modelo estratégico, eficiente y transparente", en Estudio Sistemático de la Ley de Contratos del Sector Público, Cizur-Menor: Aranzadi, págs. 47-132.

GRAJAL CABALLERO, I. (2009): "Análisis de diversos aspectos de la figura del contrato menor en las Entidades Locales a la luz de la Ley 30/2007, de 30 de octubre, de Contratos del Sector Público", en Consultor de los Ayuntamientos y Juzgados: Revista técnica especializada en administración local y justicia municipal, núm. 20, págs. 2.955-2.978.

JIMÉNEZ FRANCO, E. (2012): "Administración pública y corrupción: iniciativas legislativas de lege ferenda para una nueva cultura de integridad", en Actualidad administrativa, núm. 5, marzo 2012, págs. 538-569.

LOPEZ DE LA RIVA CARRASCO, F. A. y ALBONIGA ITURBE, J. M. (2018): "La nueva regulación del contrato menor en la Ley 9/2017, de 8 de noviembre, de Contratos del Sector Público", en Consultor de los Ayuntamientos y Juzgados: Revista técnica especializada en administración local y justicia municipal, núm. 3, págs. 70-78.

MARTINEZ FERNANDEZ, J. M. (2016): "Cerco a los contratos menores", en Revista de Estudios Locales (CUNAL), núm. 194, págs. 38-54.

MARTINEZ FERNANDEZ, J. M. (2017): "Medidas de transparencia como antídoto contra la corrupción en la contratación púbica", en Revista Jurídica de Castilla y León, núm. 41, págs. 1-46.

MARTINEZ FERNANDEZ, J. M. (2017): "La imprescindible necesidad de anticipación para afrontar las limitaciones de los contratos menores que impone la nueva ley de contratos del sector público", en Consultor de los Ayuntamientos y Juzgados: Revista técnica especializada en administración local y justicia municipal, núm. 20, págs. 2.425-2.439.

MARTINEZ FERNANDEZ, J. M. (2018): "Medidas para facilitar a las PYMEs la participación en la contratación pública", en Contratación Administrativa Práctica: revista de la contratación administrativa y de los contratistas, núm. 153, págs. 94-103. 
MEDINA ARNAIZ, T. (2013): "Las disposiciones financieras de la Unión Europea y su aplicación a la contratación pública: especial referencia al nuevo Reglamento financiero y sus normas de desarrollo", en Observatorio de los contratos públicos 2012, Cizur Menor: Aranzadi, págs. 165-191, y en especial, 188-190.

MEDINA ARNÁIZ, T. (2010): "Las respuestas normativas al fenómeno de la corrupción en la contratación pública", en Diario La Ley, núm. 7.382, abril 2010, págs. 1-10.

MORENO IBAÑEZ, I. (2018): "Comentarios al nuevo régimen jurídico de los contratos menores en la Ley 9/2017, de 8 de noviembre, de Contratos del Sector Público", en Actualidad Administrativa, núm. 3.

MORENO MOLINA, J. A. (2015): "Principios Generales de la Contratación Pública en el reciente Derecho Internacional, Europeo y de América Latina", en Revista Derecho \& Sociedad, núm. 44, págs. 55-64.

MORENO MOLINA, J. A. (2013): "La cuarta generación de Directivas de la Unión Europea sobre contratos Públicos", en Observatorio de los Contratos Públicos 2012, Cizur Menor: Aranzadi, págs. 115-163.

MORENO MOLINA, J. A. (2008): "La insuficiente incorporación del derecho Comunitario de la contratación pública en la Ley de Contratos del Sector Público", en Revista Aragonesa de Administración Pública, núm. 32, Monográfico X.

PINTOS SANTIAGO, J. (2016): "El derecho de la Unión Europea como ordenamiento jurídico global administrativo y de la contratación pública", en Contratación Administrativa Práctica: revista de la contratación administrativa y de los contratistas, núm. 144, págs. 94-103.

RAZQUIN LIZARRAGA, M. M. a y VAQUEZ MATILLA, F. J. (2017): La adjudicación de contratos públicos en la nueva Ley de Contratos del Sector Público, Cizur Menor: Aranzadi.

VELAZQUEZ NAVARRETE, P. (2015): "La excepcionalidad del contrato menor", en Administración de Andalucía: revista andaluza de la administración pública, núm. 93, págs. 389-401.

VILLANUEVA CUEVAS, A. (2016): "La contratación pública local en el borrador de anteproyecto de Ley de Contratos del Sector Público”, en Contratación Administrativa Práctica: revista de la contratación administrativa y de los contratistas, núm. 145, págs. 104-113.

VILLORIA MENDIETA, M. y JIMENEZ SÁNCHEZ, F. (2012): “La corrupción en España (2004-2010): datos, percepción y efectos”, en REIS, núm. 138, abril-junio de 2012, págs. 109-134. DOI: https://doi.org/10.5477/cis/ reis. 138.109. 